\title{
Data assimilation for continuous global assessment of severe conditions over terrestrial surfaces
}

\author{
Clément Albergel ${ }^{1, \text { a }}$, Yongjun Zheng ${ }^{1}$, Bertrand Bonan ${ }^{1}$, Emanuel Dutra $^{2}$, Nemesio Rodríguez-Fernández ${ }^{3}$, \\ Simon Munier ${ }^{1}$, Clara Draper ${ }^{4}$, Patricia de Rosnay ${ }^{5}$, Joaquin Muñoz-Sabater ${ }^{5}$, Gianpaolo Balsamo ${ }^{5}$, \\ David Fairbairn ${ }^{5}$, Catherine Meurey ${ }^{1}$, and Jean-Christophe Calvet ${ }^{1}$ \\ ${ }^{1}$ CNRM, Université de Toulouse, Météo-France, CNRS, Toulouse, France \\ ${ }^{2}$ Instituto Dom Luiz, IDL, Faculty of Sciences, University of Lisbon, Lisbon, Portugal \\ ${ }^{3}$ CESBIO, Université de Toulouse, CNRS, CNES, IRD, Toulouse, France \\ ${ }^{4}$ CIRES/NOAA Earth System Research Laboratories, Boulder, CO, USA \\ ${ }^{5}$ European Centre for Medium-Range Weather Forecasts, Shinfield Road, Reading RG2 9AX, UK \\ ${ }^{a}$ now at: European Space Agency Climate Office, ECSAT, Harwell Campus, Oxfordshire, Didcot OX11 0FD, UK
}

Correspondence: Clément Albergel (clement.albergel@meteo.fr)

Received: 7 October 2019 - Discussion started: 25 October 2019

Revised: 8 July 2020 - Accepted: 30 July 2020 - Published: 2 September 2020

\begin{abstract}
LDAS-Monde is a global offline land data assimilation system (LDAS) that jointly assimilates satellitederived observations of surface soil moisture (SSM) and leaf area index (LAI) into the ISBA (Interaction between Soil Biosphere and Atmosphere) land surface model (LSM). This study demonstrates that LDAS-Monde is able to detect, monitor and forecast the impact of extreme weather on land surface states. Firstly, LDAS-Monde is run globally at $0.25^{\circ}$ spatial resolution over 2010-2018. It is forced by the state-of-the-art ERA5 reanalysis (LDAS_ERA5) from the European Centre for Medium Range Weather Forecasts (ECMWF). The behaviour of the assimilation system is evaluated by comparing the analysis with the assimilated observations. Then the land surface variables (LSVs) are validated with independent satellite datasets of evapotranspiration, gross primary production, sun-induced fluorescence and snow cover. Furthermore, in situ measurements of SSM, evapotranspiration and river discharge are employed for the validation. Secondly, the global analysis is used to (i) detect regions exposed to extreme weather such as droughts and heatwave events and (ii) address specific monitoring and forecasting requirements of LSVs for those regions. This is performed by computing anomalies of the land surface states. They display strong negative values for LAI and SSM in 2018 for two regions: north-western Europe and the Murray-Darling basin in south-eastern Australia. For those
\end{abstract}

regions, LDAS-Monde is forced with the ECMWF Integrated Forecasting System (IFS) high-resolution operational analysis (LDAS_HRES, $0.10^{\circ}$ spatial resolution) over 2017 2018. Monitoring capacities are studied by comparing openloop and analysis experiments, again against the assimilated observations. Forecasting abilities are assessed by initializing 4 and $8 \mathrm{~d}$ LDAS_HRES forecasts of the LSVs with the LDAS_HRES assimilation run compared to the open-loop experiment. The positive impact of initialization from an analysis in forecast mode is particularly visible for LAI that evolves at a slower pace than SSM and is more sensitive to initial conditions than to atmospheric forcing, even at an $8 \mathrm{~d}$ lead time. This highlights the impact of initial conditions on LSV forecasts and the value of jointly analysing soil moisture and vegetation states.

\section{Introduction}

Extreme events are likely to increase in frequency and/or magnitude as a result of anthropogenic climate change (IPCC, 2012; Ionita et al., 2017). Amongst all the natural disasters, droughts are arguably the most detrimental (Bruce, 1994; Obasi, 1994; Cook et al., 2007; Mishra and Singh, 2010; WMO, 2017), as about one-fifth of damages caused by natural hazards can be attributed to droughts (Wil- 
hite, 2000). They cost society billions of dollars every year (WMO, 2017). It is therefore important for communities to develop tools that can monitor and predict drought conditions (Svoboda et al., 2002; Luo and Wood, 2007; Blyverket et al., 2019) as well as their impact on land surface variables (LSVs) and society (Di Napoli et al., 2019). A major scientific challenge in relation to the adaptation to climate change is to observe and simulate how land biophysical variables respond to those extreme events (IPCC, 2012).

Droughts are generally caused by a lack of precipitation. However, different drought types are classified according to the part of the hydrological cycle that suffers from a water deficit (IPCC, 2014; Barella-Ortiz and Quintana-Seguí, 2019). They include meteorological droughts (lack of precipitation), agricultural droughts (deficit of water in the soil), hydrological droughts (deficit of streamflow or water level in rivers) and environmental droughts (a combination of the previous drought types). Because of the effect of precipitation deficit on the whole hydrological system, all drought types are related (Wilhite, 2000). Complex interactions between continental surface and atmospheric processes have to be combined with human action in order to fully understand the wide-ranging impacts of droughts on land surface conditions (Van Loon, 2015). As a consequence, land surface models (LSMs) driven by high-quality gridded atmospheric variables and coupled to river-routing systems are key tools to address these challenges (Dirmeyer et al., 2006; Schellekens et al., 2017). Initially developed to provide boundary conditions to atmospheric models, LSMs can now be used to monitor and forecast land surface conditions (Balsamo et al., 2015, 2018; Schellekens et al., 2017). Additionally, the representation of LSVs by LSMs can be improved by coupling LSMs with other models of the Earth system like atmosphere, oceans and river routing (e.g. de Rosnay et al., 2013, 2014; Kumar et al., 2018; Balsamo et al., 2018; RodríguezFernández et al., 2019; Muñoz-Sabater et al., 2019).

Earth observations (EOs) provide long-term records, which can complement LSMs. Satellite products are particularly relevant for the monitoring of LSVs. Satellite EOs related to the terrestrial hydrological, vegetation and energy cycles are now available globally, at kilometric scales and below (e.g. Lettenmaier et al., 2015; Balsamo et al., 2018). Combining EOs and LSMs through land data assimilation systems (LDASs) can lead to enhanced initial land surface conditions (e.g. Reichle et al., 2007; Lahoz and De Lannoy, 2014; Kumar et al., 2018; Albergel et al., 2017, 2018a, 2019; Balsamo et al., 2018). Subsequently, this can benefit weather forecasts, including temperature and precipitation. It can also indirectly benefit agricultural and vegetation productivity prediction, streamflow prediction, warning systems for floods and droughts and the representation of the carbon cycle (Bamzai and Shukla, 1999; Schlosser and Dirmeyer, 2001; Bierkens and van Beek, 2009; Koster et al., 2010; Bauer et al., 2015; Massari et al., 2018; Albergel et al., 2018a, 2019; Rodríguez-Fernández et al., 2019; Muñoz-
Sabater et al., 2019). Amongst the current land-only LDAS activities, several are led by NASA (National Aeronautics and Space Administration) projects. Examples of such activities are the Global Land Data Assimilation System (GLDAS, Rodell et al., 2004), the North American Land Data Assimilation System (NLDAS, Xia et al., 2012a, b) and the National Climate Assessment-Land Data Assimilation System (NCA-LDAS, Kumar et al., 2016, 2018, 2019). The Famine Early Warning Systems Network (FEWS NET) Land Data Assimilation System (FLDAS, McNally et al., 2017) is run over western, eastern and southern Africa. Additional examples include the Carbon Cycle Data Assimilation System (CCDAS, Kaminski et al., 2002), the Coupled Land Vegetation LDAS (CLVLDAS, Sawada and Koike, 2014; Sawada et al., 2015), the Data Assimilation System for Land Surface Models using CLM4.5 (Fox et al., 2018) and the SMAP (Soil Moisture Active Passive) level 4 system (Reichle et al., 2019). Finally, LDAS-Monde (Albergel et al., 2017, 2018, 2019) was developed by the research department of MétéoFrance. Details of these studies are provided by Kumar et al. (2018) and Albergel et al. (2019), but few applications are global and include the assimilation of multiple EOs.

LDAS-Monde consists in an offline (i.e. non-coupled with the atmosphere) joint assimilation of surface soil moisture (SSM) and leaf area index (LAI) EOs into the ISBA (Interaction between Soil Biosphere and Atmosphere) LSM (Noilhan and Planton, 1989; Noilhan and Mahfouf, 1996). Several previous studies using LDAS-Monde have been published at regional and continental scales (Albergel et al., 2017, 2018, 2019; Leroux et al., 2018; Tall et al., 2019; Blyverket et al., 2019; Bonan et al., 2020). In this study, LDAS-Monde is run at the global scale and is forced by the latest atmospheric reanalysis (ERA5) from the European Centre for Medium Range Weather Forecasts (ECMWF), over 2010-2018. The resulting $0.25^{\circ}$ spatial resolution reanalysis of the LSVs is hereafter referred to as LDAS_ERA5. In this paper, it is shown that LDAS-Monde can be used to detect, monitor and forecast the impact of extreme events on LSVs. The following items are presented and discussed.

- An evaluation of LDAS-Monde at a global scale is carried out. This assessment involves the assimilated observations to demonstrate that the system is working as intended. Importantly, LDAS-Monde is then validated using diverse, independent and complementary satellite-derived datasets of evapotranspiration (EVAP) from the GLEAM project (Miralles et al., 2011; Martens et al., 2017), gross primary production (GPP) from the FLUXCOM project (Tramontana et al., 2016, Jung et al., 2017), solar-induced fluorescence (SIF) from the GOME-2 (Global Ozone Monitoring Experiment-2) scanning spectrometer (Munro et al., 2006, Joiner et al., 2016) and snow-cover data from the Interactive Multisensor Snow and Ice Mapping System (IMS, https:// www.natice.noaa.gov/ims/, last access: June 2019). Ad- 
ditional validations are performed with in situ measurements of evapotranspiration from the FLUXNET 2015 synthesis dataset (http://fluxnet.fluxdata.org/, last access: June 2019), soil moisture from the International Soil Moisture Network (ISMN, Dorigo et al., 2011, 2015, https://ismn.geo.tuwien.ac.at/en/, last access: June 2019) and river discharge from several networks across the world.

- The LDAS-Monde global analysis over 2010-2018 is used to detect droughts and heatwave events in 2018 . This identification is performed by computing anomalies of LSVs over the 9-year period and identifying where the strongest negative anomalies are located in 2018. For the identified regions, the abilities of LDASMonde to forecast such events in near-real time is investigated by forcing it with high-resolution forecasts from the ECMWF.

The paper is organized into five sections: Sect. 2 details the various components constituting LDAS-Monde (the ISBA LSM, the data assimilation scheme, the EOs assimilated as well as the different atmospheric forcing datasets used), followed by the experimental and evaluation setups. Section 3 describes and discusses the impact of the analysis on the representation of the LSVs. Section 4 details the identification of two case studies over regions particularly affected by extreme heatwave events during 2018. Furthermore, the detailed monitoring and land surface forecasts of these events are presented at higher spatial resolution. Finally, Sect. 5 provides conclusions and prospects for future work.

\section{Material and methods}

The following subsections briefly describe the main components of LDAS-Monde: the ISBA LSM, its data assimilation scheme and two other key elements of the setup: atmospheric forcing and assimilated satellite-derived observations. The experimental setup and the evaluation datasets used in this study are also presented.

\subsection{LDAS-Monde}

LDAS-Monde (Albergel et al., 2017) is embedded within the SURFEX (SURFace EXternalisée, Masson et al., 2013, version 8.1) modelling platform developed by the research department of Météo-France (CNRM, Centre National de Recherches Météorologiques). It allows the joint integration of satellite-derived SSM and LAI into the $\mathrm{CO}_{2}$-responsive (Calvet, et al., 1998, 2004; Gibelin et al., 2006), multilayer diffusion scheme (Boone et al., 2000; Decharme et al., 2011) version of the ISBA LSM (Noilhan and Planton, 1989; Noilhan and Mahfouf, 1996). LDAS-Monde can also be coupled with the CTRIP (CNRM Total Runoff Integrating Pathways, Decharme et al., 2019) hydrological model using a simplified extended Kalman filter (SEKF, Mahfouf et al., 2009).

\subsubsection{ISBA land surface model}

The ISBA LSM aims to model the evolution of LSVs. In the chosen configuration for this study, ISBA is able to represent the transfer of water and heat through the soil based on a multilayer diffusion scheme as well as plant growth and leaf-scale physiological processes. ISBA models key vegetation variables like LAI, above-ground biomass and the diurnal cycle of water, carbon and energy fluxes. In ISBA, the soil-vegetation composite is computed using a singlesource energy budget. In the $\mathrm{CO}_{2}$-responsive version of ISBA, ISBA-A-gs, the model can simulate the $\mathrm{CO}_{2}$ net assimilation and GPP by considering the functional relationship between the photosynthesis rate (A) and the stomatal aperture (gs) based on the biochemical A-gs model proposed by Jacob et al. (1996). Photosynthesis controls the evolution of vegetation variables. It makes vegetation growth possible as a result of an uptake of $\mathrm{CO}_{2}$. Contrastingly, a deficit of photosynthesis triggers higher mortality rates. Ecosystem respiration (RECO) represents the $\mathrm{CO}_{2}$ being released by the soil-plant system and GPP by the carbon uptake via photosynthesis. Finally, the net ecosystem exchange (NEE) consists of the difference between GPP and RECO. Each ISBA grid cell is composed of up to 12 generic land surface types, namely bare soil, rocks, permanent snow and ice surfaces, as well as 9 plant functional types (needleleaf trees, evergreen broadleaf trees, deciduous broadleaf trees, C3 crops, C4 crops, C4 irrigated crops, herbaceous, tropical herbaceous and wetlands). The ECOCLIMAP-II land cover database (Faroux et al., 2013) provides these parameters for each patch and each grid cell of the ISBA model.

The ISBA multilayer diffusion scheme's default discretization is 14 layers over $12 \mathrm{~m}$ depth. This study follows Decharme et al. (2011), which is illustrated in Fig. 1 of their paper. The thickness (depth) of each layer is (from top to bottom) $1 \mathrm{~cm}(0-1 \mathrm{~cm}), 3 \mathrm{~cm}(1-4 \mathrm{~cm}), 6 \mathrm{~cm}(4-10 \mathrm{~cm}), 10 \mathrm{~cm}$ $(10-20 \mathrm{~cm}), 20 \mathrm{~cm}(20-40 \mathrm{~cm}), 20 \mathrm{~cm}(40-60 \mathrm{~cm}), 20 \mathrm{~cm}$ $(60-80 \mathrm{~cm}), 20 \mathrm{~cm}(80-100 \mathrm{~cm}), 50 \mathrm{~cm}(100-150 \mathrm{~cm}), 50 \mathrm{~cm}$ $(150-200 \mathrm{~cm}), 100 \mathrm{~cm}(200-300 \mathrm{~cm}), 200 \mathrm{~cm}(300-500 \mathrm{~cm})$, $300 \mathrm{~cm}(500-800 \mathrm{~cm})$ and $400 \mathrm{~cm}(800$ to $1200 \mathrm{~cm})$. Snow is represented using the ISBA 12-layer explicit snow scheme (Boone and Etchevers, 2001; Decharme et al., 2016).

\subsubsection{CTRIP river-routing system}

The ISBA-CTRIP river-routing system is able to simulate continental-scale hydrological variables based on a set of three prognostic equations. They correspond to (i) the groundwater, (ii) the surface stream water and (iii) the seasonal floodplains. It converts the runoff simulated by ISBA into river discharge. The ISBA-CTRIP river-routing network has a spatial resolution of $0.5^{\circ}$ globally and is coupled daily with ISBA through the OASIS3-LCT coupler (Voldoire et al., 2017). ISBA provides CTRIP with updated fields of runoff, drainage, groundwater and floodplain recharges. In 
(a)

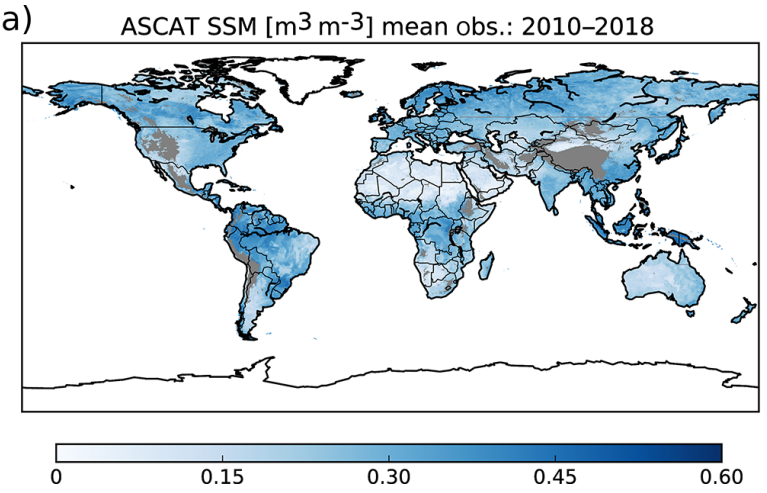

(b)

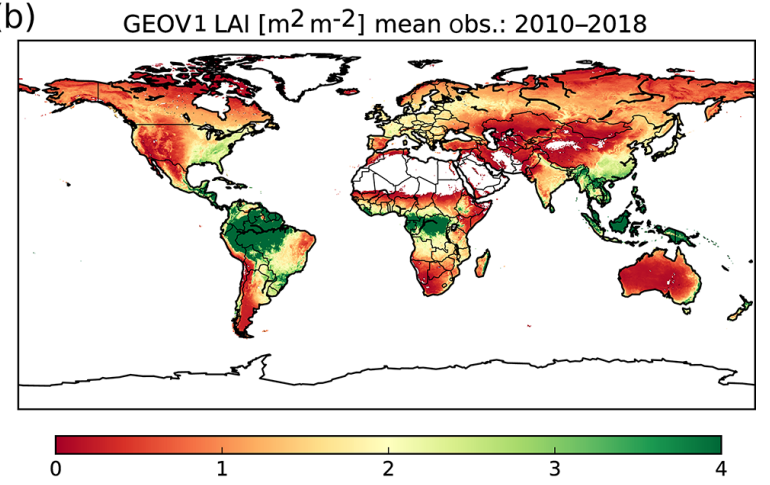

Figure 1. (a) Surface soil moisture (SSM) from the Copernicus Global Land Service (CGLS) for pixels with less than $15 \%$ of urban areas and with an elevation of less than 1500 ma.s.l. (b) GEOV1 leaf area index (LAI) from CGLS, for pixels covered by more than $90 \%$ of vegetation, averaged over 2010 to 2018. SSM is obtained after rescaling the ASCAT Soil Wetness Index (SWI) to the model climatology; grey areas in (a) represent filtered-out data (see Sect. 2.3).

turn, CTRIP provides ISBA with water table depth, floodplain fraction as well as flood potential infiltration. Subsequently, ISBA can simulate capillary rise, evaporation and infiltration over flooded areas. A comprehensive overview of how CTRIP is coupled with ISBA is available in Decharme et al. (2019).

\subsubsection{Data assimilation}

The SEKF used in LDAS-Monde is a two-step sequential approach in which a prior forecast step is followed by an analysis step. The prior forecast propagates the initial states to the next time step with the ISBA LSM and the analysis step then corrects this forecast by assimilating observations. The flow dependency (dynamic link) between the prognostic variables and the observations is ensured in the SEKF through the observation operator and its Jacobians, which propagate information from the observations to the analysis via finitedifference computations (de Rosnay et al., 2013). The Jacobian matrix has as many rows as assimilated observation types (two in our case: SSM and LAI) and as many columns as model control variables requested (eight in our case, soil moisture from layers 2 to 8 and LAI). In addition to a control run (i.e. the forecast step), computing the Jacobian matrix requires perturbed runs, one for each control variable. The eight control variables are directly updated using their sensitivity to observed variables (i.e. defined by the Jacobian). Other variables are indirectly modified through biophysical processes and feedback from the model. Several studies (e.g. Draper et al., 2009; Rüdiger et al., 2010) have demonstrated that small perturbations lead to a good linear approximation of the model behaviour, provided that computational roundoff error is not significant. Typically, for those runs, the initial state of the control variable is perturbed by about $0.1 \%$ (see Albergel et al., 2017; Rüdiger et al., 2010). The length of the LDAS-Monde assimilation window is $24 \mathrm{~h}$. A mean volumetric standard deviation error of $0.04 \mathrm{~m}^{3} \mathrm{~m}^{-3}$ is pre-

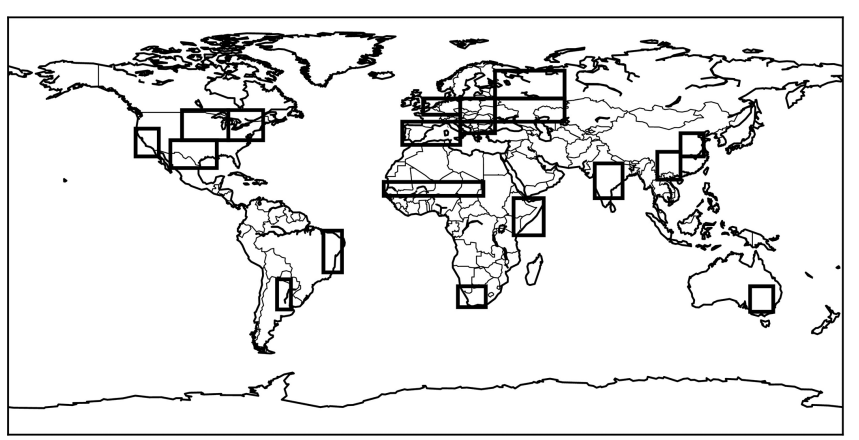

Figure 2. Selection of 19 regions across the globe known for being potential hotspots for droughts and heatwaves. The regions are defined in Table 1.

scribed for soil moisture in the second layer of soil (i.e. the model equivalent of the observations, between 1 and $4 \mathrm{~cm}$ ): it is $0.02 \mathrm{~m}^{3} \mathrm{~m}^{-3}$ for soil moisture in deeper layers (soil layers 3 to $8,4-100 \mathrm{~cm}$ ). Both are then scaled by the dynamic range of soil moisture (the difference between the volumetric field capacity and the wilting point, calculated as a function of the soil type, as given by Noilhan et Mahfouf, 1996). The observational SSM error follows the same approach and a value of $0.05 \mathrm{~m}^{3} \mathrm{~m}^{-3}$ is used. This is consistent with errors typically expected for remotely sensed SSM (e.g. de Jeu et al., 2008, Gruber et al., 2016). Based on previous results from Jarlan et al. (2008), Rüdiger et al. (2010) and Barbu et al. (2011), observed LAI standard deviation errors are set to $20 \%$ of the LAI value itself. The LAI prior forecast errors are set equivalent to the observation errors for values higher than $2 \mathrm{~m}^{2} \mathrm{~m}^{-2}$. For values lower than $2 \mathrm{~m}^{2} \mathrm{~m}^{-2}$, a fixed standard deviation error of $0.04 \mathrm{~m}^{2} \mathrm{~m}^{-2}$ has been used. More details about this approach can be found in Barbu et al. (2011) (Sect. 2.3 and Fig. 2). 
Table 1. Continental hotspots for droughts and heatwaves and number of monthly anomalies SSM and LAI below -1 standard deviation (SD) and above $1 \mathrm{SD}$ in 2018 with respect to the 2010-2018 period.

\begin{tabular}{|c|c|c|c|c|c|c|c|}
\hline Region name & Abbreviation & LON-W & LON-E & LAT-S & LAT-N & $\begin{array}{r}\text { Number of monthly } \\
\text { SSM anomalies below } \\
-1 \text { (above 1) SD }\end{array}$ & $\begin{array}{r}\text { Number of monthly } \\
\text { LAI anomalies below } \\
-1 \text { (above } 1 \text { ) SD }\end{array}$ \\
\hline Western Europe & WEUR & -1 & 15 & 48 & 55 & $5(1)$ & $5(0)$ \\
\hline Western Mediterranean & WMED & -10 & 15 & 35 & 45 & $0(7)$ & 4(4) \\
\hline Eastern Europe & EEUR & 15 & 30 & 45 & 55 & $2(1)$ & $0(2)$ \\
\hline Balkans & BALK & 15 & 30 & 40 & 45 & $3(3)$ & 1(4) \\
\hline Western Russia & WRUS & 30 & 60 & 55 & 67 & $0(1)$ & 1(3) \\
\hline Lower Volga & LVOL & 30 & 60 & 45 & 55 & $2(1)$ & $2(1)$ \\
\hline India & INDI & 73 & 85 & 12 & 27 & $3(0)$ & $2(1)$ \\
\hline South-western China & SWCH & 100 & 110 & 20 & 32 & $0(2)$ & $0(6)$ \\
\hline Northern China & $\mathrm{NRCH}$ & 110 & 120 & 30 & 40 & $0(3)$ & $0(4)$ \\
\hline Murray-Darling & MUDA & 140 & 150 & -37 & -26 & $6(0)$ & $7(0)$ \\
\hline California & CALF & -125 & -115 & 30 & 42 & $2(0)$ & $5(0)$ \\
\hline Southern Plains & SPLN & -110 & -90 & 25 & 37 & $0(3)$ & $0(4)$ \\
\hline Midwest & MIDW & -105 & -85 & 37 & 50 & $1(2)$ & 1(3) \\
\hline Eastern north & ENRT & -85 & -70 & 37 & 50 & $0(3)$ & $0(7)$ \\
\hline Nordeste & NDST & -44 & -36 & -20 & -2 & $0(3)$ & $1(2)$ \\
\hline Pampas & PAMP & -64 & -58 & -36 & -23 & $2(2)$ & $2(0)$ \\
\hline Sahel & SAHL & -18 & 25 & 13 & 19 & $2(0)$ & $1(2)$ \\
\hline Eastern Africa & EAFR & 38 & 51 & -4 & 12 & $2(3)$ & 1(7) \\
\hline Southern Africa & SAFR & 14 & 26 & -35 & -26 & $2(0)$ & $2(1)$ \\
\hline
\end{tabular}

\subsection{Atmospheric forcing}

The lowest level of the atmospheric model (about $10 \mathrm{~m}$ a.g.l.) of air temperature, wind speed, specific humidity and pressure, the downwelling fluxes of shortwave and longwave radiations as well as precipitation (partitioned into solid and liquid phases) are needed to force LDAS-Monde. In this study, LDAS-Monde is driven by several near-surface meteorological fields from the ECMWF:

- its most recent atmospheric reanalysis (ERA5) to produce an LDAS-Monde global reanalysis;

- its high-resolution Integrated Forecast System (IFS HRES) to monitor and predict the evolution of LSVs for regions under severe droughts and heatwaves.

ERA5 (Hersbach et al., 2018, 2020) is the fifth generation of global reanalyses produced by the ECWMF. This atmospheric reanalysis is a key element of the Copernicus Climate Change Service (C3S) and is available from 1979 onward (data are released about 2 months behind real time). ERA5 produces analyses at an hourly output and at $31 \mathrm{~km}$ horizontal resolution and consists of 137 levels in the vertical. Several studies have validated the ERA5 dataset. For example, Urraca et al. (2018) have compared incoming solar radiation from both ERA5 and the ERA-Interim reanalysis (Dee et al., 2011) at a global scale and found evidence that ERA5 outperforms ERA-Interim. In another study, Beck et al. (2019) have highlighted the good performance of ERA5 precipita- tion with respect to a set of 26 gridded (sub-daily) precipitation data sources by comparing them to Stage-IV gauge-radar data over the CONUS domain (CONtinental United States of America). Tall et al. (2019) have used in situ measurements of precipitation at more than 100 stations spanning all over Burkina Faso in western Africa as well as incoming solar radiation from four in situ stations. They evaluated the performance of ERA5 compared to ERA-Interim and found improved results for ERA5 as well. Furthermore, they evaluated both reanalysis datasets for their ability to force the ISBA LSM, which demonstrates a clear advantage for ERA5 in terms of the performance of LSVs. Albergel et al. (2018a) made similar comparisons of the ISBA LSM forcing over North America. They showed enhanced performances in the representation of evapotranspiration, snow depth, soil moisture and river discharge for ERA5 relative to ERA-Interim.

At the time of writing, the ERA5 model and data assimilation system (cycle 41r2 of the ECMWF IFS) are very similar to that of the operational weather forecast, HRES, which has production cycles ranging from $41 \mathrm{r} 2$ to $45 \mathrm{r} 1$ during the study period (more information at https://www.ecmwf.int/en/forecasts/ documentation-and-support/changes-ecmwf-model, last access: July 2019). The main difference between ERA5 and HRES over the considered period is the horizontal resolution, consisting of $9 \mathrm{~km}$ in HRES and $31 \mathrm{~km}$ in ERA5. The atmospheric forcing is interpolated from the native grids of ERA5 and HRES to regular grids at $0.25^{\circ}$ and $0.1^{\circ}$ respectively, using a bilinear interpolation from the native 
grid to the regular grid. ERA5 and HRES were used in Albergel et al. (2019) to force LDAS-Monde in order to study the impact of the 2018 summer heatwave in Europe. Authors have highlighted that the HRES configuration (LDAS_HRES hereafter) exhibits better monitoring skills than the coarser-resolution ERA5 configuration.

In forecasting mode, the HRES forecast is also available daily from 00:00 UTC with a $10 \mathrm{~d}$ lead time. The HRES forecast step frequency is hourly up to time step 90 (i.e. day 3), 3-hourly from time steps 90 to 144 (i.e. day 6) and 6-hourly from time steps 144 to 240 (i.e. day 10). In the forecast experiments in this study (see Sect. 2.4 for details on the experimental setup) HRES forecasts with a $10 \mathrm{~d}$ lead time are used to force the LSM forecasts of the LSVs. By comparing LDAS_HRES open-loop and analysis configurations it is possible to evaluate the impact of the initialisation on the forecast of LSVs. The original 3-hourly time steps are used up to day 6 (time step 144). The 6-hourly time steps from days 6 to 10 are interpolated to 3-hourly frequency to avoid discontinuities.

\subsection{Assimilated satellite Earth observations}

Two types of satellite-derived variables are assimilated in LDAS-Monde: ASCAT soil water index (SWI) and LAI GEOV1. They are both freely available through the Copernicus Global Land Service (CGLS, https://land.copernicus. eu/global/index.html, last access: June 2019).

ASCAT stands for Advanced Scatterometer, which is an active C-band microwave sensor that is onboard the European MetOp polar orbiting satellites (METOP-A from 2006, -B from 2012 and also -C from 2019). From ASCAT radar backscatter coefficients, it is possible to derive information on SSM following a change detection approach (Wagner et al., 1999; Bartalis et al., 2007). The recursive form of an exponential filter (Albergel et al., 2008) is then applied to estimate the SWI using a timescale parameter, $T$ (varying between 1 and $100 \mathrm{~d}$ ). $T$ is a surrogate parameter for all the processes potentially affecting the temporal dynamics of soil moisture, including soil hydraulic properties, soil layer thickness, evaporation, runoff and vertical gradient of soil properties. The obtained SWI then ranges between 0 (dry) and 100 (wet). In this study, CGLS SWI-001 (produced with a $T$ value of $1 \mathrm{~d}$ ) is used as a proxy for SSM (Kidd et al., 2013). Grid points with an average altitude exceeding $1500 \mathrm{~m}$ a.s.l. as well as those with more than $15 \%$ of urban land cover are rejected as those conditions are known to inhibit the retrieval of SSM from space. Prior to the assimilation, SSM has to be converted from the observation space to the model space. This is done through a linear rescaling as proposed by Scipal et al. (2007), where the mean and variance of observations are matched to the mean and variance of the modelled soil moisture from the second layer of soil (1-4 cm depth). In practice, the rescaling gives similar results to CDF (cumulative distribution function) matching. The linear rescal- ing is performed on a seasonal basis (with a 3-month moving window) as suggested by Draper et al. (2011) and Barbu et al. (2014).

The LAI GEOV1 observations are based on data from both SPOT-VGT (up to 2014) and PROBA-V (from 2014) satellites. They span from 1999 to present, have $1 \mathrm{~km}$ spatial resolution and are produced according to the methodology developed by Baret et al. (2013). LAI GEOV1 observations have a temporal frequency of $10 \mathrm{~d}$ at best and no observations are available during cloudy conditions. LAI data are masked in the presence of modelled snow by the ISBA LSM.

As in previous studies (e.g. Barbu et al., 2014; Albergel et al., 2019), observations are interpolated by an arithmetic average to the model grid points $\left(0.25^{\circ}\right.$ or $0.10^{\circ}$ in this study) if at least $50 \%$ of the model grid points are observed (i.e. half the maximum amount). ASCAT SSM and LAI GEOV1 are illustrated by Fig. 1.

\subsection{Experimental setup}

LDAS-Monde is first run globally, at $0.25^{\circ}$ spatial resolution, forced by the ERA5 atmospheric reanalysis. It assimilates both SSM and LAI EOs from 2010 to 2018 (LDAS_ERA5). LDAS_ERA5 is spun up by running the year 201020 times. The LDAS_ERA5 analysis and its model counterpart (openloop, i.e. no data assimilation) are presented and evaluated in this study.

This 9-year global reanalysis is then used to provide a monthly climatology for estimating anomalies of the land surface conditions. For each month (and variable considered) of 2018 we have removed the monthly mean and scaled by the monthly standard deviation of the 2010-2018 period. Significant anomalies are used to trigger more detailed monitoring and forecasting activities for a region of interest. A total of 19 regions across the globe have been selected, which are known for being potential hotspots for droughts and heatwaves. They are listed in Table 1 and presented in Fig. 2. Monthly anomalies of SSM and LAI in the LDAS_ERA5 analysis are calculated for 2018 (with respect to the 20102018 period) over these 19 regions. In turn, regions presenting significant levels of negative anomalies are selected and further investigated. For those regions, a new LDAS-Monde experiment was driven by the HRES atmospheric analysis, leading to a $0.1^{\circ}$ analysis of the LSVs from April 2016 to December 2018 (LDAS_HRES). Note that HRES is only available at a $0.1^{\circ}$ spatial resolution from April 2016. April to December 2016 is used as a short period for spin-up and results are presented for the period 2017-2018. Although a 9-month spin-up period is rather short, evaluating LDAS_HRES over either 2017-2018 or 2018 (using instead a 21-month spinup) leads to similar results on surface soil moisture and LAI (not shown). While the system is not fully spun up, it is long enough to capture the system response to data assimilation. LDAS_HRES complements the coarser spatial resolution LDAS_ERA5. 
HRES forecasts with a $10 \mathrm{~d}$ lead time are initialized either from LDAS_HRES analysis or open-loop experiments (LDAS_Fc hereafter) in order to assess the impact of the initialization on the forecast. For simplicity, only forecasts with a 4 and $8 \mathrm{~d}$ lead time are presented (LDAS_fc 4 and LDAS_fc8 respectively). A summary of the experimental setup is given in Table 2 .

\subsection{Evaluation datasets and metrics}

Both satellite-derived estimates of EOs and in situ measurements are used as reference datasets in this study. The LDAS_ERA5 analysis performance is assessed with respect to the open-loop model run (i.e. no assimilation). The two assimilated datasets, CGLS SSM and LAI, are firstly used to verify that the data assimilation is behaving as expected. Then several independent datasets are used for the validation, namely evapotranspiration from the GLEAM project (Miralles et al., 2011; Martens et al., 2017, version 3b, entirely satellite driven), GPP from the FLUXCOM project (Tramontana et al., 2016; Jung et al., 2017), SIF from the GOME2 (Global Ozone Monitoring Experiment-2) scanning spectrometer (Munro et al., 2006; Joiner et al., 2016) and snowcover data from the Interactive Multi-sensor Snow and Ice Mapping System (IMS, https://www.natice.noaa.gov/ims/, last access: August 2020). The IMS snow-cover product combines ground observations and satellite data from microwave and visible sensors (using geostationary and polarorbiting satellites) to provide snow-cover information in all weather conditions. The IMS product is available daily for the Northern Hemisphere.

Soil moisture is validated using in situ measurements of soil moisture from the ISMN, a pool of stations which consists of 19 networks across 14 countries (see Table S3 in the Supplement). In total, 782 stations are represented with at least 2 years of daily data over 2010-2018. In situ measurements at $5 \mathrm{~cm}$ depth (SSM) are compared with soil moisture from the third layer of soil $(4-10 \mathrm{~cm})$ in LDAS_ERA5. In situ measurements at $20 \mathrm{~cm}$ depth are compared with LDAS_ERA5 soil moisture from the fourth layer of soil (10$20 \mathrm{~cm}, 685$ stations from 10 networks). Besides 11 stations located in four countries of western Africa (Benin, Mali, Sénégal and Niger) and 21 stations in Australia, most of the stations are located in North America and Europe (see Table S3).

Evaluation datasets are listed in Table 3 along with the metrics used for the evaluation. For satellite datasets of SWI, LAI, evapotranspiration and GPP, the metrics consist of the correlation coefficient $(R)$, root mean square differ-

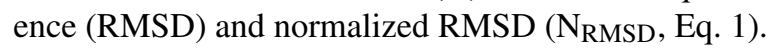

$\mathrm{N}_{\mathrm{RMSD}}=\frac{\mathrm{RMSD}_{\text {(Analysis) }}-\mathrm{RMSD}_{\text {(Model) }}}{\mathrm{RMSD}_{\text {(Model) }}} \times 100$

Regarding the SIF satellite dataset, fluorescence is not simulated directly in the ISBA LSM. However, photosynthe- sis activity is simulated through the calculation of the GPP, which is driven by plant growth and mortality in the model. Modelled GPP values are expressed in $g(C) \mathrm{m}^{-2} \mathrm{~d}^{-1}$, while SIF is an energy flux emitted by the vegetation $\left(\mathrm{mW} \mathrm{m} \mathrm{m}^{-2} \mathrm{sr}^{-1} \mathrm{~nm}^{-1}\right)$. Hence, GPP and SIF cannot be directly compared as they do not represent the same physical quantities. However, several studies (e.g. Zhang et al., 2016; Sun et al., 2017; Leroux et al., 2018) have found a high correspondence in both time and space between those two variables, highlighting the potential of SIF products to support the validation of modelled GPP. Therefore, the correlation between modelled GPP and observed SIF is used as an evaluation metric. Concerning the snow-cover dataset, differences between observed and modelled snow cover are considered for the evaluation.

For in situ datasets of soil moisture and evapotranspiration, the standard metrics are considered, namely the correlation coefficient, RMSD, unbiased RMSD and bias. Moreover, a normalized information contribution (NIC, Eq. 2) measure is applied to the correlation values to quantify the improvement or degradation due to the specific configuration.

$\mathrm{NIC}_{R}=\frac{R_{(\text {Analysis })}-R_{(\text {Model })}}{1-R_{(\text {Model })}} \times 100$

NIC scores are classified according to three categories: (i) negative impact from the analysis with respect to the openloop with values smaller than $-3 \%$, (ii) positive impact from the analysis with respect to the open-loop with values greater than $+3 \%$ and (iii) neutral impact from the analysis with respect to the open-loop with values between $-3 \%$ and $3 \%$.

In addition, for surface soil moisture, the correlation is calculated for both absolute $(R)$ and anomaly $\left(R_{\text {anomaly }}\right)$ time series in order to remove the strong impact from the SSM seasonal cycle (see e.g. Albergel et al., 2018a, b).

The Nash-Sutcliffe efficiency score (NSE, Nash and Sutcliffe, 1970, Eq. 3) is used to evaluate LDAS_ERA5 experiments' ability to represent the monthly discharge dynamics.

$$
\mathrm{NSE}=1-\frac{\sum_{\mathrm{mt}=1}^{T}\left(Q_{s}^{\mathrm{mt}}-Q_{\mathrm{o}}^{\mathrm{mt}}\right)^{2}}{\sum_{\mathrm{mt}=1}^{t}\left(Q_{s}^{\mathrm{mt}}-\overline{Q_{s}^{\mathrm{mt}}}\right)^{2}},
$$

where $Q_{s}^{\mathrm{mt}}$ is the monthly river discharge from LDAS_ERA5 (analysis or open-loop) at month $\mathrm{mt}$, and $Q_{\mathrm{o}}^{\mathrm{mt}}$ is the observed river discharge at month mt. NSE can vary between $-\infty$ and 1. An exact match between model predictions and observed data is defined as a value of 1 , whereas a value of 0 means that the model predictions have the same accuracy as the mean of the observed data. Finally, negative values represent situations where the observed mean is a better predictor than the model simulation. NIC presented in Eq. (1) has also been applied to NSE scores to assess the added value of LDAS_ERA5 analysis over its open-loop counter- 
Table 2. Setup of the experiments performed in this study. LDAS_ERA5 and LDAS_HRES have an analysis (assimilation of surface soil moisture, SSM, and leaf area index, LAI) and a model equivalent (open-loop, no assimilation); LDAS_fc4 and LDAS_fc8 are model runs initialized by either LDAS_HRES open-loop or analysis. n/a stands for not applicable.

\begin{tabular}{|c|c|c|c|c|c|c|c|}
\hline $\begin{array}{l}\text { Experiments } \\
\text { (time period) }\end{array}$ & Model version & $\begin{array}{l}\text { Atmospheric } \\
\text { forcing }\end{array}$ & $\begin{array}{l}\text { Domain and } \\
\text { spatial resolution }\end{array}$ & $\begin{array}{l}\text { DA } \\
\text { method }\end{array}$ & $\begin{array}{l}\text { Assimilated } \\
\text { observations }\end{array}$ & $\begin{array}{l}\text { Model } \\
\text { equivalents }\end{array}$ & $\begin{array}{l}\text { Control } \\
\text { variables }\end{array}$ \\
\hline $\begin{array}{l}\text { LDAS_ERA5 } \\
\text { (2010 to 2018) }\end{array}$ & \multirow{4}{*}{$\begin{array}{l}\text { ISBA multi- } \\
\text { layer soil } \\
\text { model } \mathrm{CO}_{2-} \\
\text { responsive } \\
\text { version } \\
\text { (interactive } \\
\text { vegetation) }\end{array}$} & ERA5 & $\begin{array}{l}\text { Global, } \sim 0.25^{\circ} \\
\times 0.25^{\circ}\end{array}$ & \multirow[t]{2}{*}{ SEKF } & $\begin{array}{l}\text { SSM } \\
(\text { ASCAT) }\end{array}$ & $\begin{array}{l}\text { Second layer } \\
\text { of soil }(1-4 \mathrm{~cm})\end{array}$ & $\begin{array}{l}\text { Layers of soil } 2 \\
\text { to } 8(1-100 \mathrm{~cm})\end{array}$ \\
\hline $\begin{array}{l}\text { LDAS_HRES } \\
\text { (April } 2016 \text { to } \\
\text { December 2018) }\end{array}$ & & \multirow[t]{3}{*}{ IFS-HRES } & $\begin{array}{l}\text { North-western } \\
\text { Europe (WEUR) } \\
\text { and Murray-Darling }\end{array}$ & & $\begin{array}{l}\text { LAI } \\
\text { (GEOV1) }\end{array}$ & LAI & LAI \\
\hline $\begin{array}{l}\text { LDAS_fc4 } \\
\text { (2017 to 2018) }\end{array}$ & & & $\begin{array}{l}\text { River basin (MUDA) } \\
\text { (see spatial extent in }\end{array}$ & \multirow[t]{2}{*}{$\mathrm{n} / \mathrm{a}$} & \multirow[t]{2}{*}{$\mathrm{n} / \mathrm{a}$} & \multirow[t]{2}{*}{$\mathrm{n} / \mathrm{a}$} & \multirow[t]{2}{*}{$\mathrm{n} / \mathrm{a}$} \\
\hline $\begin{array}{l}\text { LDAS_fc8 } \\
\text { (2017 to 2018) }\end{array}$ & & & $\begin{array}{l}\text { Table 1) } \sim 0.10^{\circ} \times \\
0.10^{\circ}\end{array}$ & & & & \\
\hline
\end{tabular}

part. Stations with NSE values less that -2 have been discarded. A similar threshold has already been used in previous studies evaluating LDAS-Monde (e.g. Albergel et al., 2017, 2018a). Many anthropogenic processes are not yet represented in ISBA, including water management from dams and reservoirs, irrigation, and water uptake in urban areas. This could lead to a poor representation of river discharges in those regions. As with previous studies it has been decided to exclude these areas by focusing on stations with reasonable NSE values.

\section{Global assessment of LDAS_ERA5}

\subsection{Gridded datasets}

In this section, the LDAS-Monde open-loop and analysis are firstly compared against the assimilated observations (SSM and LAI) to demonstrate that the assimilation system is working as intended. Both experiments are also compared with independent sources of information to evaluate the analysis impact (GPP, EVAP and SIF).

Figure 3 presents mean LAI RMSD values between the observations and LDAS_ERA5 for the open-loop (Fig. 3a) and for the analysis (Fig. 3b) over 2010-2018. Because LAI observations are ingested into the model, the assimilation reduces the LAI RMSD values almost everywhere. It should be noted that rather large LAI RMSD values $\left(>1.5 \mathrm{~m}^{2} \mathrm{~m}^{-2}\right)$ can remain in some areas after the assimilation, especially in densely forested areas.

Figure 4 illustrates latitudinal plots of LAI, SSM, GPP and EVAP for LDAS_ERA5 before assimilation (the open-loop) and after assimilation (the analysis) along with observations. The number of points considered per $0.25^{\circ}$ stripe is also represented. From Fig. $4 \mathrm{a}$ it is possible to see the positive impact the analysis has on LAI compared to the open-loop, with the former being closer to the observations. Improvements in the analysis fit are visible between nearly $80^{\circ} \mathrm{N}$ and about $55^{\circ} \mathrm{S}$, and areas around the Equator are impacted the most from the assimilation. This demonstrates that the data assimilation system is working as intended. A smaller impact is obtained for SSM, GPP and EVAP relative to LAI, which is hardly visible at this scale. The mean latitudinal results show a consistent difference in terms of GPP and EVAP between LDAS_ERA5 and the observational products. These differences are systematic with higher values in tropical regions.

Figure 5 presents latitudinal plots of score differences (correlations and $\mathrm{N}_{\mathrm{RMSD}}$ ) for LAI, SSM, GPP, EVAP and SIF. For SIF, it only makes sense to show the correlation differences, since this metric is used to evaluate GPP variability as in Leroux et al. (2018). Score differences are computed by subtracting the open-loop from the analysis. Monthly averages are calculated over 2010-2018 for LAI and SSM, 20102013 for GPP, 2010-2016 for EVAP and 2010-2015 for SIF. For each panel of Fig. 5, the vertical dashed line represents the 0 value. For plots of correlation differences, positive values indicate an improvement in the analysis with respect to the open-loop simulation. Similarly, for plots of RMSD differences, negative values indicate an improvement in the analysis with respect to the open-loop simulation. Given that LAI and SSM are assimilated variables, the analysis leads to a clear improvement in both correlation and RMSD. Such an improvement is expected and reflects the healthy behaviour of the assimilation system. Both variables are improved at almost all latitudes, with the exception around $45^{\circ} \mathrm{S}$ for LAI correlation values (very few land points). For SSM a noticeable improvement in both correlation and RMSD is found around $20^{\circ} \mathrm{N}$, which corresponds mainly to an improvement in the Sahara (not shown). Being linked to LAI, GPP is also improved across almost all latitudes (to a lesser extent than LAI), with a particularly positive impact below $20^{\circ} \mathrm{N}$. As seen in Fig. 5d and i, there is a negligible impact of the assimilation on EVAP. It highlights the difficulty of land surface data assimilation in impacting model fluxes by modifying model states. 
Table 3. Evaluation datasets and associated metrics used in this study. All URLs in this table were last accessed in August 2020.

\begin{tabular}{|c|c|c|c|}
\hline Datasets used for the evaluation & Source & Metrics associated & $\begin{array}{l}\text { Independent } \\
\text { source } \\
\text { of evaluation }\end{array}$ \\
\hline $\begin{array}{l}\text { In situ measurements of soil moisture } \\
\text { (ISMN, Dorigo et al., 2011, 2015) }\end{array}$ & https://ismn.geo.tuwien.ac.at/en/ & $\begin{array}{l}R \text { for both absolute and anomaly } \\
\text { time series, unbiased RMSD and } \\
\text { bias, NIC on } R \text { values }\end{array}$ & Yes \\
\hline In situ measurements of river discharge & See Table S1 & $\begin{array}{l}\text { Nash-Sutcliffe efficiency (NSE), } \\
\text { normalized information contribu- } \\
\text { tion (NIC) based on NSE }\end{array}$ & Yes \\
\hline $\begin{array}{l}\text { In situ measurements of evapotranspi- } \\
\text { ration (FLUXNET-2015) }\end{array}$ & $\begin{array}{l}\text { http://fluxnet.fluxdata.org/data/ } \\
\text { fluxnet2015-dataset/ }\end{array}$ & $\begin{array}{l}R, \text { unbiased RMSD, bias, NIC on } \\
R \text { values }\end{array}$ & Yes \\
\hline $\begin{array}{l}\text { Satellite-derived surface soil wetness } \\
\text { index (ASCAT, Wagner et al., 1999; } \\
\text { Bartalis et al., 2007) }\end{array}$ & http://land.copernicus.eu/global/ & $R, \mathrm{RMSD}$ and $\mathrm{N}_{\mathrm{RMSD}}$ & $\begin{array}{l}\text { No } \\
\text { (assimilated } \\
\text { dataset) }\end{array}$ \\
\hline $\begin{array}{l}\text { Satellite-derived leaf area index } \\
\text { (GEOV1, Baret et al., 2013) }\end{array}$ & http://land.copernicus.eu/global/ & $R, \mathrm{RMSD}$ and $\mathrm{N}_{\mathrm{RMSD}}$ & $\begin{array}{l}\text { No } \\
\text { (assimilated } \\
\text { dataset) }\end{array}$ \\
\hline $\begin{array}{l}\text { Satellite-driven model estimates of } \\
\text { land evapotranspiration (GLEAM, } \\
\text { Martens et al., 2017) }\end{array}$ & http://www.gleam.eu & $R, \mathrm{RMSD}$ and $\mathrm{N}_{\mathrm{RMSD}}$ & Yes \\
\hline $\begin{array}{l}\text { Upscaled estimates of gross primary } \\
\text { production (GPP, Jung et al., 2017) }\end{array}$ & $\begin{array}{l}\text { https://www.bgc-jena.mpg.de/ } \\
\text { geodb/projects/Home.php }\end{array}$ & $R, \mathrm{RMSD}$ and $\mathrm{N}_{\mathrm{RMSD}}$ & Yes \\
\hline $\begin{array}{l}\text { Solar-induced fluorescence (SIF) from } \\
\text { GOME-2 (Munro et al., 2006; Joiner et } \\
\text { al., 2016) }\end{array}$ & See references & $R$ & Yes \\
\hline $\begin{array}{l}\text { Interactive Multi-sensor Snow and Ice } \\
\text { Mapping System (or IMS) snow cover }\end{array}$ & $\begin{array}{l}\text { https://www.natice.noaa.gov/ } \\
\text { ims/ }\end{array}$ & Differences & Yes \\
\hline
\end{tabular}

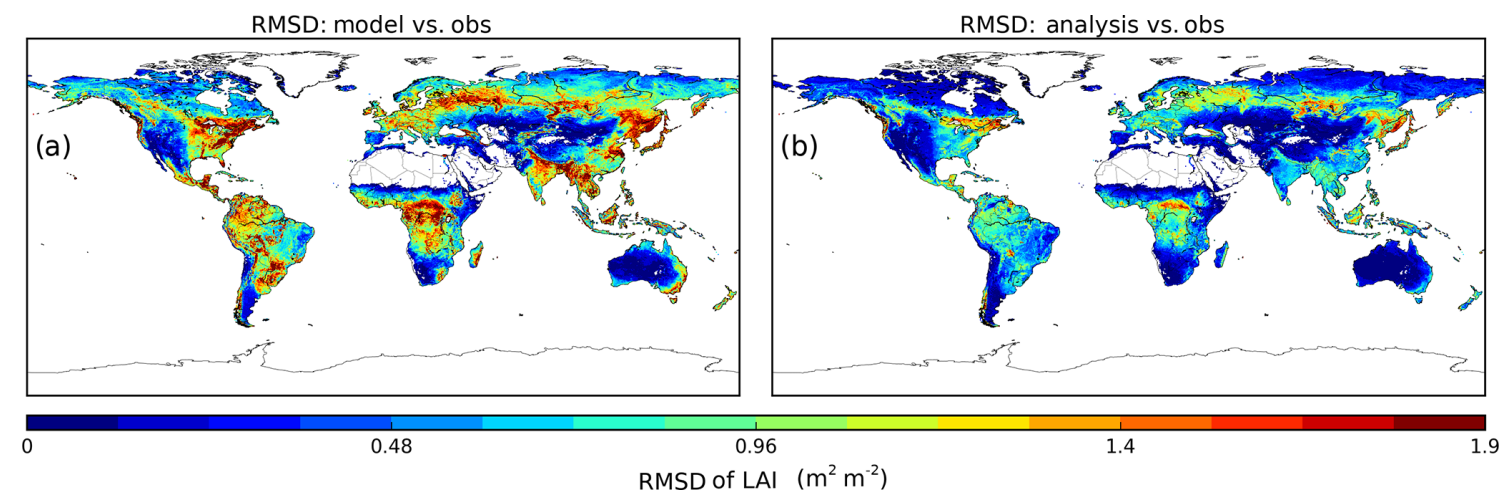

Figure 3. RMSD values between observed leaf area index (LAI) and LDAS_ERA5 (a) before assimilation and (b) after assimilation of surface soil moisture (SSM) and LAI.

The panels of Fig. 6 illustrate histograms of score differences (correlation and RMSD, analysis minus open-loop) for LAI, SSM, GPP, EVAP and SIF. The number of available data and the percentage of positive and negative values are reported. For correlations (RMSD) differences, posi- tive (negative) values indicate an improvement in the analysis relative to the open-loop. Regarding LAI, the analysis improves $96.9 \%$ of the grid points for correlations and $99.9 \%$ for $\mathrm{N}_{\mathrm{RMSD}}$. As for SSM, correlation values are improved for $92.8 \%$ of the grid points ( $92.4 \%$ for RMSD). 


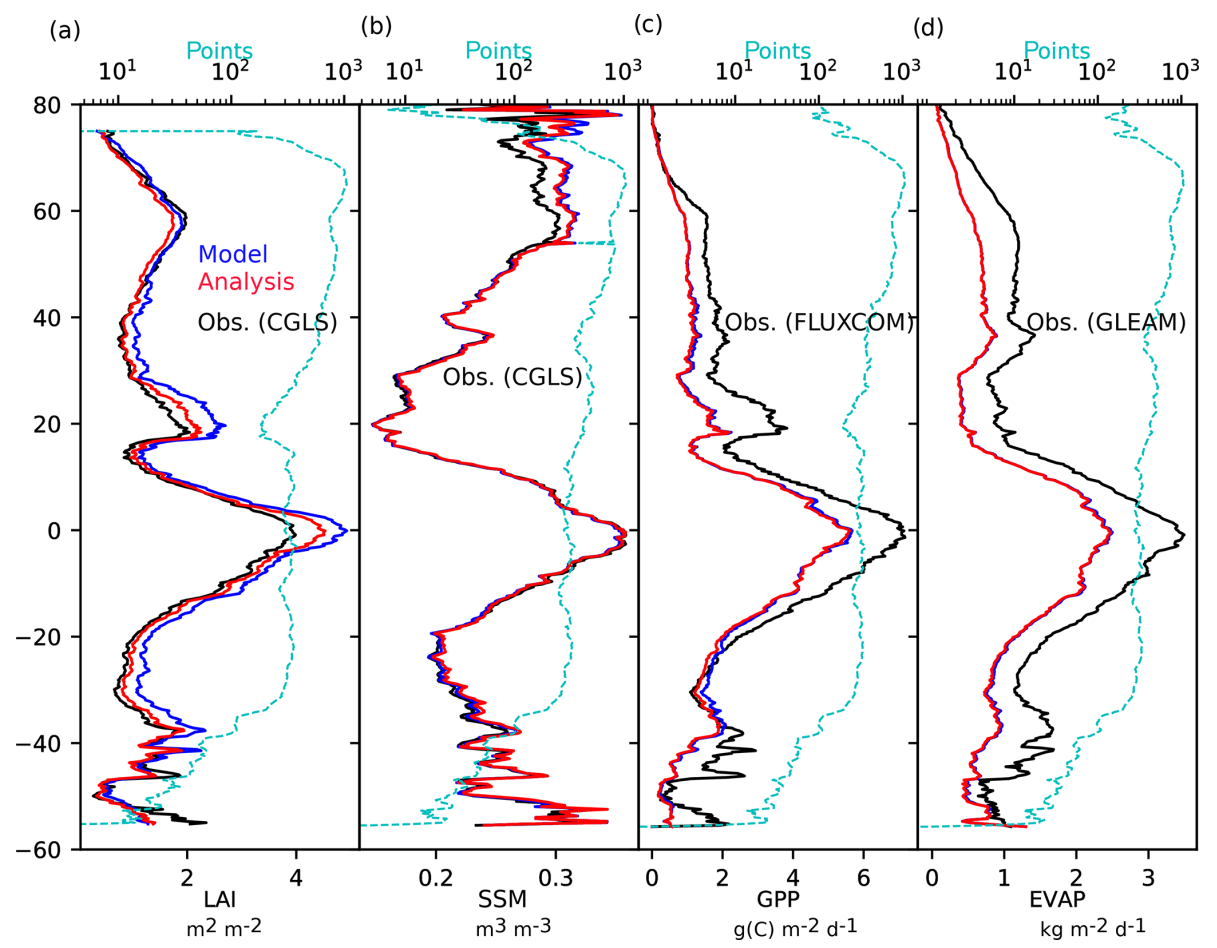

Figure 4. Latitudinal plots of (a) leaf area index (LAI), (b) surface soil moisture (SSM), (c) gross primary production (GPP) and (d) evapotranspiration (EVAP) for LDAS_ERA5 before assimilation (model, blue solid line) and after assimilation (analysis, red solid line) as well as observations (black solid line). Cyan dashed line represents the number of points considered per latitudinal stripe of $0.25^{\circ}$.

The independent GPP and SIF datasets also demonstrate improvements in the analysis relative to the open-loop. Indeed, the GPP correlation (RMSD) is better for $81.1 \%(74.1 \%)$ of the grid points and the SIF correlation is enhanced for $79.7 \%$. Results using the GLEAM dataset for evapotranspiration are more contrasting with $63.6 \%(48.9 \%)$ of the grid points showing an improvement from the analysis. It is worth mentioning that $24.9 \%(39.6 \%)$ of the grid point shows a decrease in skill. However, GLEAM is an evaporation model designed to be driven by remote sensing observations only. GLEAM only estimates (root-zone) soil moisture and terrestrial evaporation, while the $\mathrm{CO}_{2}$-responsive version of ISBA in LDAS_ERA5 is a physically based land surface model, accounting for more processes linked to vegetation (see Sect. 2.1.1). It should be noted that the auxiliary datasets used to represent the different land cover types also differ. Within GLEAM, the land cover types are sourced from the Global Vegetation Continuous Fields product (MOD44B), based on observations from the Moderate Resolution Image Spectroradiometer (MODIS). Four land cover types are considered, namely bare soil, low vegetation (e.g. grass), tall vegetation (e.g. trees), and open water (e.g. lakes). In ISBA, the fraction of the 12 land cover types over some areas departs from prevalent land cover products such as CLC2000 (Corine Land Cover) and GLC2000 (Global Land Cover). It could potentially impact the distribution of the terrestrial evaporation between GLEAM and ISBA. Further work at CNRM will focus on understanding the differences between ISBA and GLEAM, in particular investigating the subcomponents of terrestrial evaporation.

Finally, Figs. S1 and S2 illustrate snow-cover evaluation. LDAS_ERA5 snow cover is evaluated against the IMS snow cover. Fig. S1 shows the averaged Northern Hemisphere snow-cover fraction for the 2010-2018 period. It is complemented by Fig. S2, which shows (i) maps of IMS snow cover (top row) for three seasons, (ii) equivalent maps of snow cover from LDAS_ERA5 open-loop (second row), (iii) maps of snow-cover differences between the open-loop and IMS data and (iv) maps of snow-cover differences between the analysis and the open-loop. LDAS_ERA5 open-loop compares very well with the IMS snow-cover data in the accumulation season from September to February (Figs. S2 and S1d to i), except for an overestimation over the Tibetan Plateau. The issue over Tibet from ERA5 is not new and is consistent with Orsolini et al. (2019). An early melt in spring is visible in LDAS_ERA5 compared to observations and could be related to the snow-cover parametrization in ISBA. As expected, the analysis has an almost neutral impact on snow as both SSM and LAI observations are filtered out during frozen/snow-covered conditions, and there is no snow data assimilation yet in LDAS_ERA5 (Figs. S2 and S1j, k and l). Clearly an area of potential improvement in LDAS-Monde is to incorporate snow data assimilation using satellite data such as IMS (as in e.g. de Rosnay et al., 2014). 


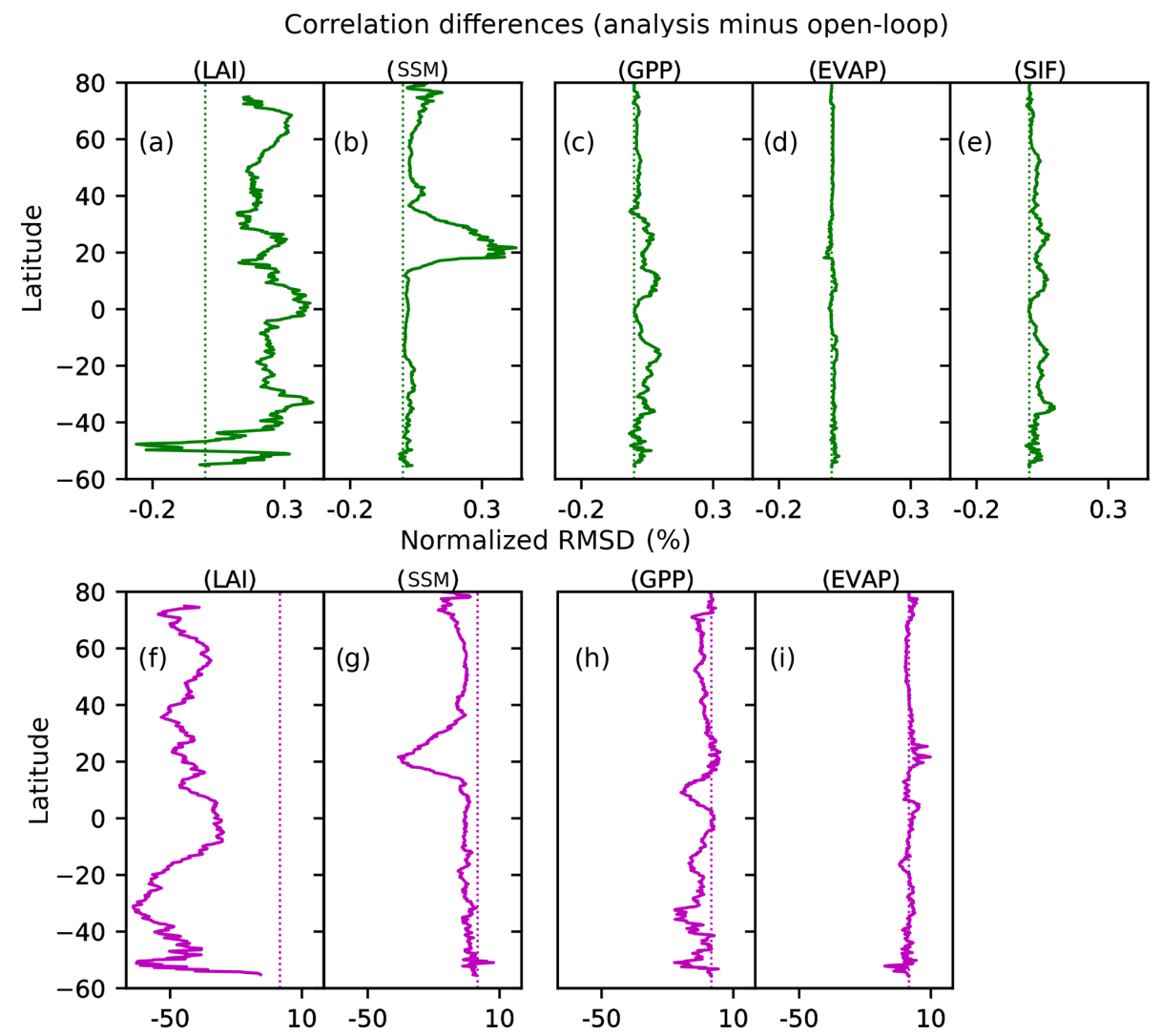

Figure 5. Latitudinal plots of score differences (analysis minus open-loop) for correlations (a-e) and normalized RMSD (f-i) for LAI (a, f), SSM (b, g), GPP (c, h), EVAP (d, i) and SIF (e, correlations only). Scores are computed based on the monthly average over 2010-2018 for LAI and SSM, 2010-2013 for GPP, 2010-2016 for EVAP and 2010-2015 for SIF. Dashed lines represent the zero lines (equal scores for open-loop and analysis).

\subsection{Ground-based datasets}

LDAS_ERA5 analysis and open-loop are also evaluated using independent in situ measurements of evapotranspiration, river discharge and surface soil moisture across the world. Daily in situ measurements of evapotranspiration from the FLUXNET-2015 synthesis dataset (http://fluxnet.fluxdata. org/, last access: June 2019) are first used in this study. The LDAS_ERA5 evapotranspiration performance is evaluated using the correlation coefficient $(R)$, RMSD, ubRMSD and the bias (LDAS_ERA5 minus observations) using the 85 selected FLUXNET-2015 stations. The median $R$, RMSD, ubRMSD and bias for LDAS_ERA5 analysis (open-loop) are 0.73 (0.72), $28.74(29.60) \mathrm{W} \mathrm{m}^{-2}, 27.37$ (26.92) $\mathrm{W} \mathrm{m}^{-2}$ and $4.64(4.40) \mathrm{W} \mathrm{m}^{-2}$ respectively. Although these values depict a small advantage of the analysis over the open-loop, it is worth mentioning that these differences are rather small and likely to fall within the uncertainty of the in situ measurements.

Figure 7a represents the added value of the analysis based on $\mathrm{NIC}_{R}$ (Eq. 2), the large blue circles represent a positive impact from the analysis (20 stations) with a $\mathrm{NIC}_{R}$ greater than +3 (i.e. $R$ values are better when the analysis is used than when the model is used), while large red circles represent a degradation from the analysis (5 stations) with a $\mathrm{NIC}_{R}$ smaller than -3 . Stations with a rather neutral impact (60 stations) have a $\mathrm{NIC}_{R}$ between $[-3 ;+3]$ and are reported using small dots. Note that at the scale of Fig. 7a, some stations are overlapping. Figure 7a is complemented by panels b, c, d and e which show scatter plots of $R$, ubRMSD, absolute bias and RMSD between LDAS_ERA5 analysis ( $x$ axis) and the open-loop ( $y$ axis) for the 85 stations from the Fluxnet 2015 . Out of the 85 stations considered, 56 have better $R$ values in the analysis compared to the open-loop. The respective numbers of improved stations for ubRMSD, RMSD and the absolute bias equate to 41,47 and 44 respectively. The set of 20 stations from Fig. 7a where the analysis has a positive impact on the $\mathrm{NIC}_{R}$ (greater than +3 ) are reported in green in Fig. $7 b$.

Results on river discharge are illustrated by Fig. 8 (panels a and b). Figure 8a represents NSE scores for the subset of 982 stations selected. Most of them are located in North America and Europe, while a few are available in South America and Africa. Figure $8 \mathrm{a}$ is complemented by Fig. 8b, which shows the NIC score applied to the NSE score. It emphasizes the 


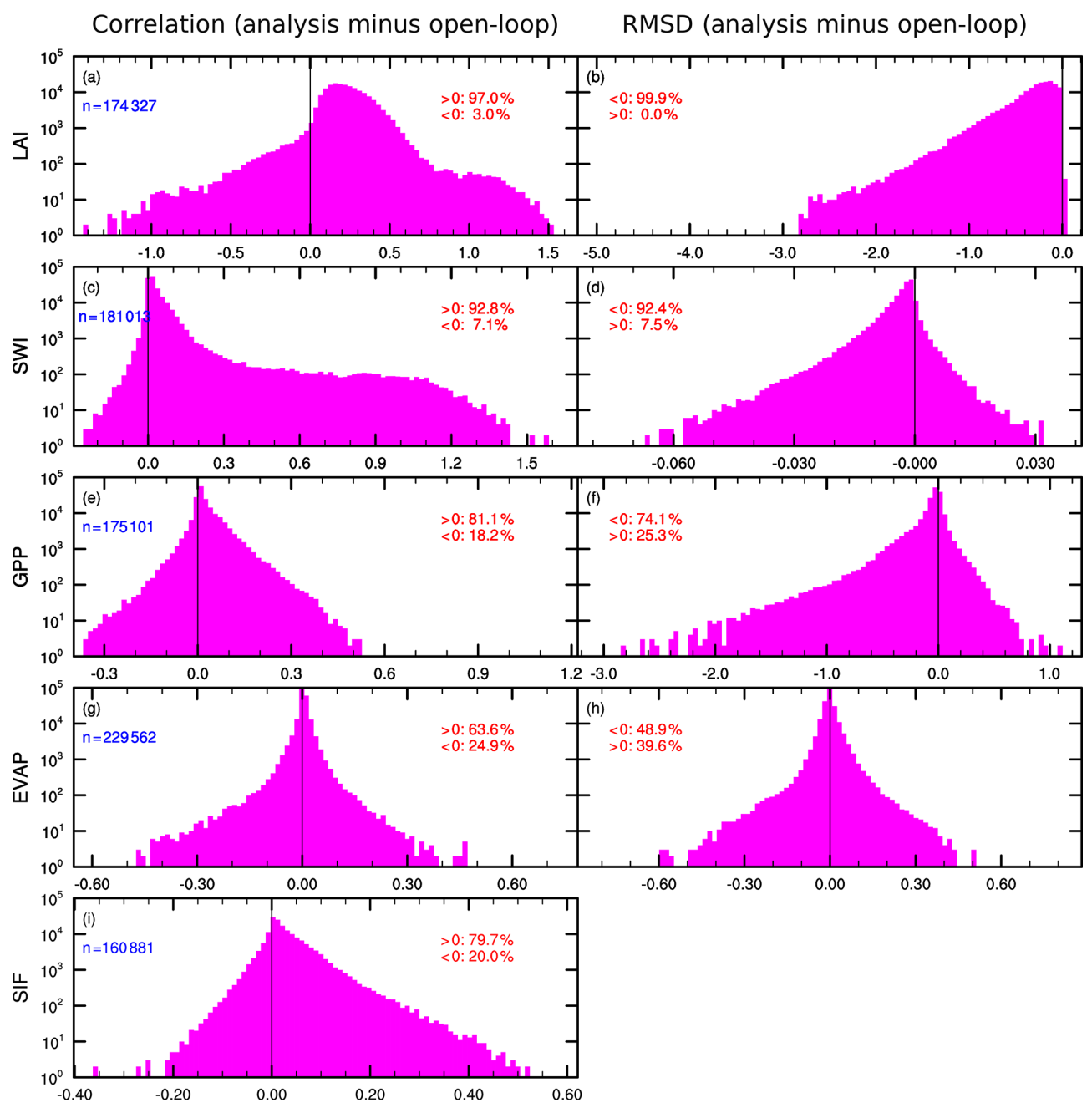

Figure 6. Histograms of score differences (correlation and RMSD, analysis minus open-loop) for (a, b) LAI, (c, d) SSM, (e, f) GPP, (g, h) EVAP and (i) SIF. For SIF only differences in correlation are represented. Number of available data (in blue) as well as the percentage of positive and negative values (in red) are reported. Note that for the sake of clarity, the $y$ axis is logarithmic.

added value of the LDAS_ERA5 analysis over the open-loop. From this subset of stations, $74 \%$ present a rather neutral impact from the analysis (with a NIC ranging between $-3 \%$ and $+3 \%$ ), while $26 \%$ (254 stations) present a significant impact (with a NIC above $+3 \%$ or below $-3 \%$ ). When the analysis significantly impacts the representation of river discharge, this impact tends to be positive. Indeed, $74 \%$ of this subset of stations ( 189 stations) have a NIC score greater than $3 \%$ while only $26 \%$ (65 stations) show NIC scores smaller than $-3 \%$.

The statistical scores for soil moisture from LDAS_ERA5 open-loop and analysis are presented for the third and fourth layers of soil, corresponding to $4-10 \mathrm{~cm}$ depth and $10-20 \mathrm{~cm}$ depth respectively. The soil moisture at layers 3 and 4 is compared with ground measurements over 2010-2018 from the ISMN at depths of 5 and $20 \mathrm{~cm}$ respectively. The results are displayed in Table S3 for each individual network. Averaged statistical scores (ubRMSD, $R, R_{\text {anomaly }}$ and bias) are similar for both LDAS_ERA5 analysis and open-loop even if local differences exist. For the analysis, averaged $R$ $\left(R_{\text {anomaly }}\right)$ values for the third layer, along with their $95 \%$ Confidence intervals (CIs) (782 stations from 19 networks) are $0.68 \pm 0.03(0.53 \pm 0.04)$. For the open-loop, the averaged $R$ ( $\left.R_{\text {anomaly }}\right)$ values are $0.67 \pm 0.03(0.53 \pm 0.04)$. Averagednetwork values are highest for the SOILSCAPE network with values of $0.88 \pm 0.01(0.58 \pm 0.04)$ for the analysis (49 stations in the USA). For all networks, the average $R$ values are higher than 0.55 , with the exception of ARM (10 stations in the USA), which presents an averaged $R$ value of $0.29 \pm 0.05$. Averaged ubRMSD and bias (LDAS_ERA5 minus in situ) are 0.060 and $0.077 \mathrm{~m}^{3} \mathrm{~m}^{-3}$ for the analysis respectively. The open-loop has a similar performance, with an ubRMSD and bias of 0.060 and $0.076 \mathrm{~m}^{3} \mathrm{~m}^{-3}$ respectively. NIC (Eq. 2) has also been applied to $R$ values. In total, $65 \%$ of stations present a neutral impact of the analysis compared to the open-loop (511 stations at NIC ranging 


\section{Normalized information contribution (NIC) based on R values, LDAS_Monde EKF-OL}

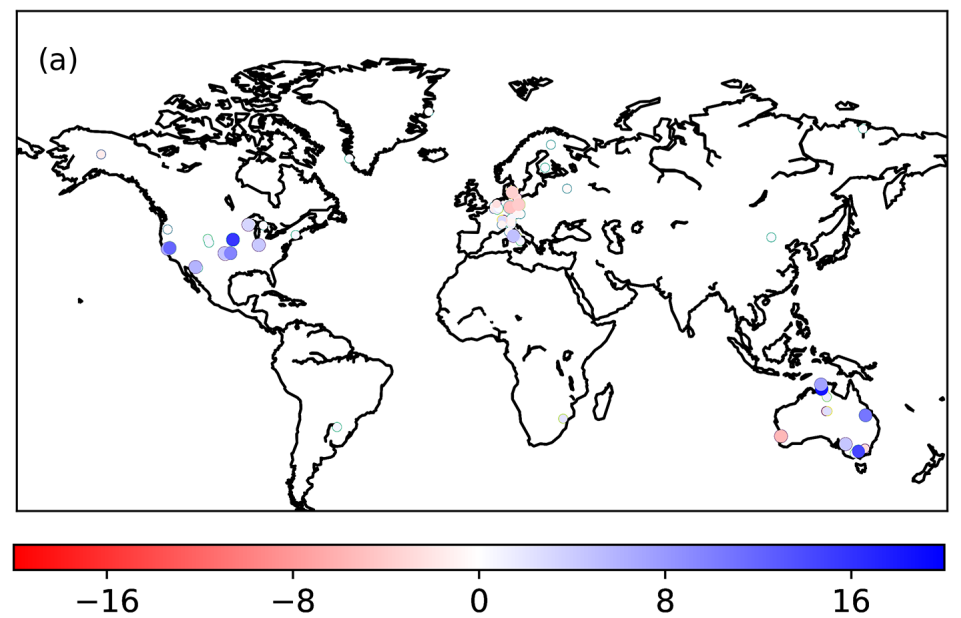

(b)

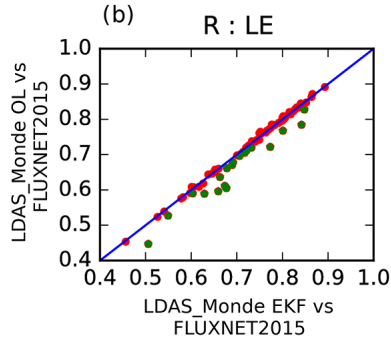

(c) UbRMSD : LE

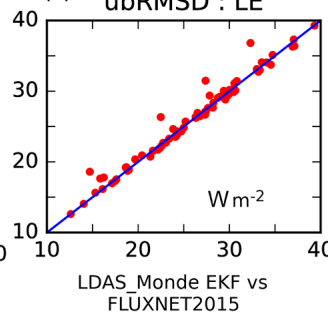

(d) abs(bias) : LE

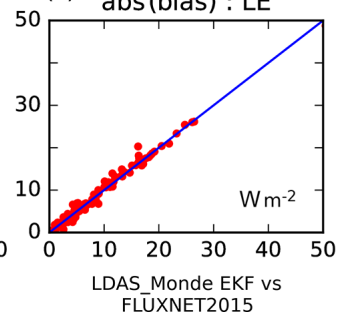

(e) RMSD : LE

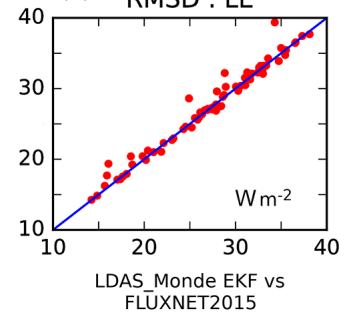

Figure 7. (a) Map of the normalized information contribution (NIC, Eq. 2) applied to correlation values between evapotranspiration from LDAS_ERA5 analysis (open-loop) and observations from the FLUXNET 2015 synthesis dataset. NIC scores are classified into two categories: (i) negative impact from the analysis with respect to the model with values smaller than $-3 \%$ (red circles, 5 stations) and (ii) positive impact from the analysis with respect to the model with values greater than $+3 \%$ (blue circles, 20 stations). Stations presenting a neutral impact with values between $-3 \%$ and $+3 \%$ (60 stations) are reported as small dots. Note that at this scale some stations are overlapping. (b, c, $\mathbf{d}$ and e) Scatter plots of $R$, ubRMSD, absolute bias and RMSD between LDAS_ERA5 open-loop and the 85 stations from the FLUXNET 2015 ( $y$ axis) and LDAS_ERA5 analysis and the same pool of stations ( $x$ axis). The set of 20 stations for which the analysis has a positive impact on $R$ values at $\mathrm{NIC}_{R}$ greater than +3 is reported in (a) in green.

between -3 and +3 ), $12 \%$ present a negative impact (91 stations at $\mathrm{NIC}<-3)$ and $23 \%$ present a positive impact (180 stations at $\mathrm{NIC}>+3$ ).

The number of stations where $R$ differences between the analysis and the open-loop are significant (i.e. their $95 \%$ CIs are not overlapping) is 186 out of 782 (about 26\%). There is an improvement from the analysis with respect to the open-loop for 128 stations (about 69\%) and a degradation for 58 stations (about $31 \%$ ). Figure 9 illustrates $R$ differences between the analysis and the open-loop runs over CONUS where most of the stations are located (552 out of 782). When differences (analysis minus open-loop) are not significant, stations are represented by a small dot (425 stations out of 552). When they are significant (127 stations out of 552), large circles have been used, with blue corresponding to positive differences (99 stations out of 127) and red to negative differences (28 stations out of 127). For most of the stations where a significant difference is obtained, it represents an improvement from the analysis.
Averaged analysis $R(95 \% \mathrm{CI})$, bias and ubRMSD for the fourth layer of soil (685 stations from 10 networks) are $0.65 \pm 0.03,0.049$ and $0.055 \mathrm{~m}^{3} \mathrm{~m}^{-3}$ respectively. For the open-loop, they are $0.64 \pm 0.03,0.048$ and $0.056 \mathrm{~m}^{3} \mathrm{~m}^{-3}$ respectively. In terms of the NIC, about $60 \%$ of the stations demonstrate a neutral impact of the analysis compared with the open-loop, while $28 \%$ show a positive impact and $12 \%$ a negative impact. Although differences between the openloop run and the analysis are rather small, these results underline the added value of the analysis with respect to the model run. Figure S3 represents the distribution of the scores values for LDAS_ERA5 open-loop and analysis using box plots centred on the median value. It is difficult to see any important differences between them.

For evapotranspiration, river discharge and surface soil moisture there is a slight advantage for the LDAS_ERA5 analysis with respect to its open-loop counterpart. Even if the averaged statistical metrics are rather similar for both, there are significant differences at the regional scale. 

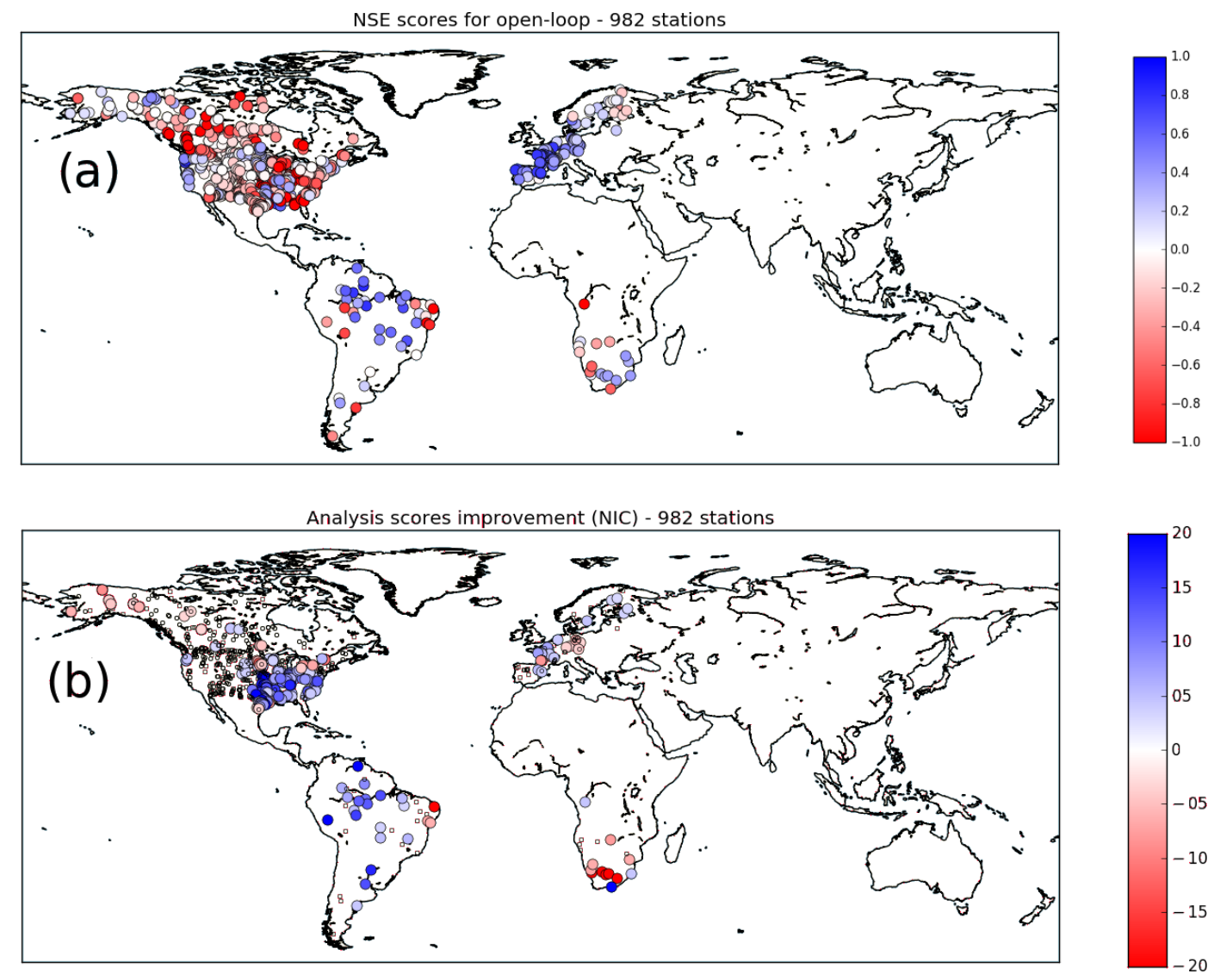

Figure 8. (a) Global map of Nash-Sutcliffe efficiency scores (NSE) between river discharge from LDAS_ERA5 open-loop and in situ measurements from the networks presented in Table S1 over 2010-2016. (b) Normalized information contribution scores (NIC, Eq. 2) based on NSE scores on river discharge. Small dots represent stations for which NICs are between $[-3 \%$, $+3 \%]$ (i.e. neutral impact from LDAS_ERA5 analysis), NIC values greater than $+3 \%$ (blue large circles) suggest an improvement from LDAS_ERA5 analysis over LDAS_ERA5 open-loop, while values smaller than $-3 \%$ (large red circles) suggest a degradation. Only stations where more than 4 years of data are available and with a drainage area greater than $10000 \mathrm{~km}^{2}$ are considered. Stations with NSE values smaller than -2 are discarded, also leading to a subset of 982 stations available.

\section{Monitoring and forecasts for areas under severe/extreme conditions}

\subsection{Selection of two regional case studies}

For each individual region presented in Table 1 and Fig. 2, monthly anomalies (scaled by the standard deviation) of analysed SSM (second layer of soil, $1-4 \mathrm{~cm}$ ) and LAI for 2018 are assessed with respect to the 2010-2018 average. The anomalies (see Fig. 10) highlight three regions, two of which present strong negative anomalies for both SSM and LAI for almost all of 2018. These are northwestern Europe (WEUR) and the Murray-Darling basin (MUDA) in south-eastern Australia. Contrastingly, eastern Africa (EAFR) presents strong positive anomalies of SSM and LAI. WEUR and MUDA regions were affected by a severe heatwave and a drought in 2018, which impacted the LSVs analysed by LDAS_ERA5. According to Fig. 10, monthly anomalies of SSM and LAI for MUDA are nega- tive through 2018, with 7 (6) months presenting LAI (SSM) anomalies below -1 standard deviation (SD) respectively. WEUR has negative SSM anomalies from May to December 2018, with values dipping below -2 SD. LAI was severely impacted as well, with July to October 2018 presenting negative anomalies below -2 SD. For WEUR, 5 months show LAI and SSM anomalies below $-1 \mathrm{SD}$. On the other hand, EAFR experienced 3 (7) months with positive anomalies for SSM and LAI in 2018 above 1 SD.

According to the National Oceanic and Atmospheric Administration (NOAA), Europe experienced its warmest summer since continental records began in 1910 with a positive anomaly at $+2.16^{\circ} \mathrm{C}$ above mean (Global Climate Report, https://www.ncdc.noaa.gov/sotc/global/, last access: April 2019). In Europe, temperatures over all the summer months in 2018 were above the climatological mean. The summer 2018 heatwave in Europe has already been reported 


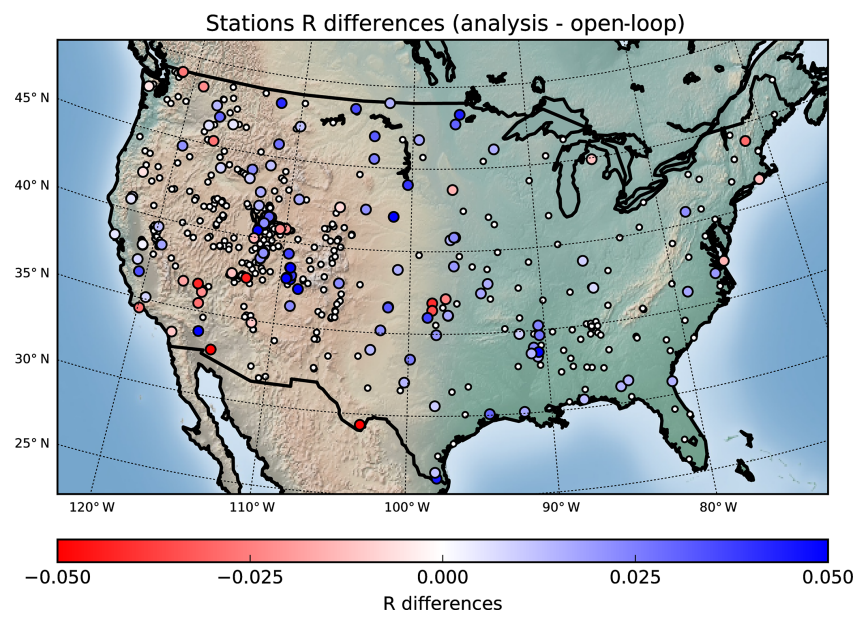

Figure 9. Map of correlation $(R)$ differences (analysis minus openloop) for stations measuring soil moisture at $5 \mathrm{~cm}$ depth and being available over North America. Small dots represent stations where $R$ differences are not significant (i.e. $95 \%$ confidence intervals are overlapping), large circles where differences are significant.
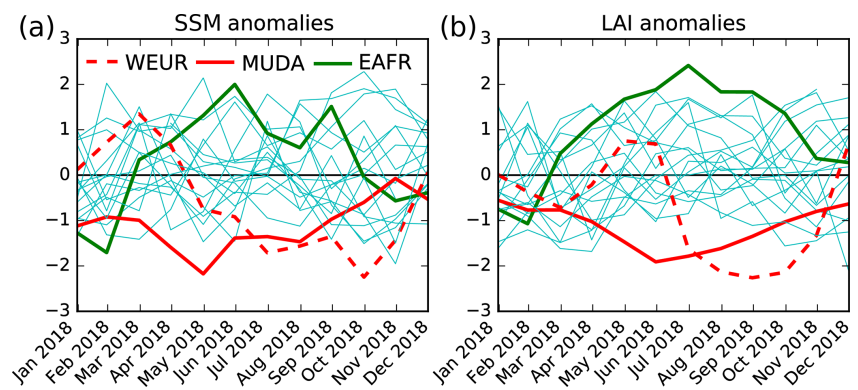

Figure 10. 2018 monthly anomalies scaled by standard deviation of analysed (a) SSM and (b) LAI, with respect to 2010-2018, for the 19 regions presented in Table 1 and Fig. 2. Solid red line, dashed red line and solid green line represent regions MUDA, WEUR and EAFR. Solid cyan line represents all other boxes (see Table 1 and Fig. 2).

in the scientific literature (e.g. Magnusson et al., 2018; Albergel et al., 2019; Blyverket et al., 2019).

In its 70th Special Climate Statement, the Australian Bureau of Meteorology (BoM) reported a very hot and dry summer 2018 in eastern Australia (BoM, 2019). Like much of Australia, the Murray-Darling basin also experienced remarkably dry and hot weather during 2018. The annual maximum temperature for the Murray-Darling basin as a whole was more than $2^{\circ}$ above average during 2018. The northern Murray-Darling basin in particular was severely affected, with inflows to all river catchments persistently well below normal (http://www.bom.gov.au/state-of-the-climate/, last access: April 2019). Finally, the East African Seasonal Monitor based on the Famine Early Warning System Network (FEWS) confirms above-average rainfall amounts and significantly greener-than-normal vegeta- tion conditions (e.g. https://reliefweb.int/report/somalia/ east-africa-seasonal-monitor-july-27-2018, last access: April 2019). As this study focuses on monitoring and forecasting the impact of severe drought conditions on LSVs, the WEUR and MUDA regions are selected for further investigation.

\subsection{Case studies: LDAS-Monde medium-resolution $\left(0.25^{\circ}\right)$ experiments}

Figure 11 illustrates seasonal cycles of observed LAI (Fig. 11a) and SWI (Fig. 11e), LDAS_ERA5 analysis and open-loop LAI (Fig. 11b) and SSM (Fig. 11f) for the WEUR domain. The 2018 period is compared to the 2010-2017 average. Figure 11a shows the heatwave impact with a sharp drop in observed LAI values from June to November 2018 (solid green line). Such low LAI values have never been observed over the 8 previous years (it is below the minimum value in shaded green). A similar behaviour is also visible in the ASCAT SWI dataset in Fig. 11e, with the lowest values recorded in 2018 for the 2010-2018 period. Over WEUR, LDAS_ERA5 open-loop overestimates LAI in the second part of the year, as already highlighted by several studies (e.g. Albergel et al., 2017, 2019). The LDAS_ERA5 analysis has a positive impact and reduces LAI values, as seen in Fig. 11b. Figure 11c, d, g and h depict a similar situation for the MUDA area: almost every month of 2018 presents the lowest values for both SSM and LAI. For both MUDA and WEUR, the smaller differences for LAI and SSM between LDAS_ERA5 analysis and open-loop in 2018 indicates that both extreme events were well captured in the atmospheric forcing used to drive LDAS_ERA5.

\subsection{Case studies: LDAS-Monde high-resolution $\left(0^{\circ}\right)^{\circ}$ analysis and forecast experiments}

For the two selected areas (WEUR and MUDA), LDASMonde is also run over April 2016 to December 2018 with the atmospheric forcing from HRES (LDAS_HRES) at $0.1^{\circ}$ spatial resolution. Additionally, daily forecast experiments are performed and the results presented for LAI and SSM for lead times of 4 and $8 \mathrm{~d}$. These forecasts are initialized by either LDAS_HRES analysis or open-loop over 20172018 in order to assess the impact of the initial conditions. In this subsection, this new set of six experiments is verified against the assimilated observations. Verification of the forecasts with these observations can be viewed as an independent validation as those observations are not assimilated yet. It is worth mentioning that there is a difference between the use of SSM and LAI observations to evaluate the forecast. For SSM, the assimilation is done after a rescaling of the observations to the model climatology (see Sect. 2.3), which removes bias. However, for LAI this is not the case, and the assimilation process removes the bias in the modelled LAI with respect to the observations. This difference, 
(a) LAI GEOV1 $\left[\mathrm{m}^{2} \mathrm{~m}^{-2}\right]$

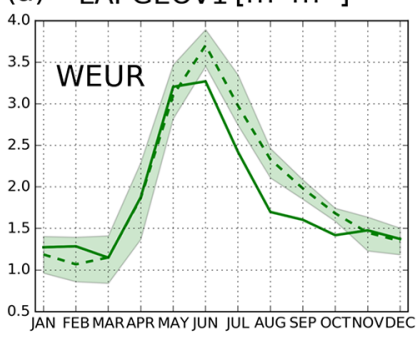

(e) SWI ASCAT [-]

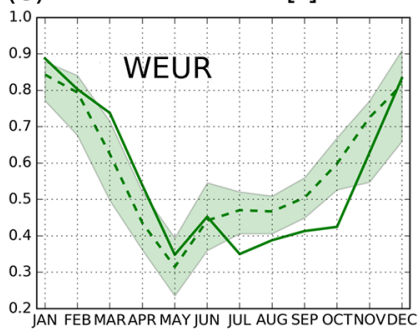

Min/max obs. 2010-01-01-2017-12-31
— Obs. 2018-01-01-2018-12-31

- Obs. 2018-01-01-2018-12-31 (b) LAI LDAS $\left[\mathrm{m}^{2} \mathrm{~m}^{-2}\right]$

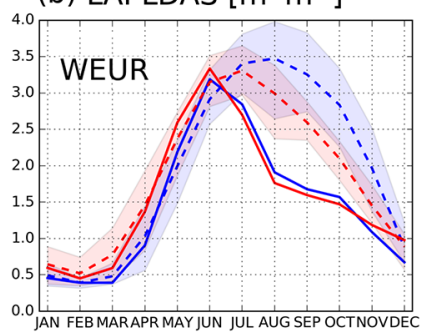

(f) $\operatorname{SSM}(1-4 \mathrm{~cm})$ LDAS $\left[\mathrm{m}^{3} \mathrm{~m}^{-3}\right]$

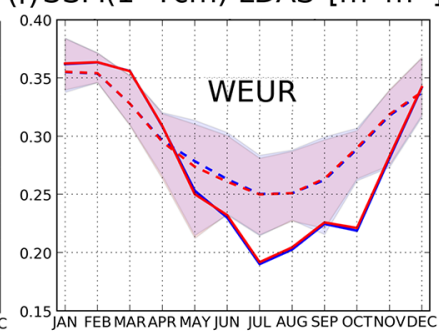

(c) LAI GEOV $1\left[\mathrm{~m}^{2} \mathrm{~m}^{-2}\right]$

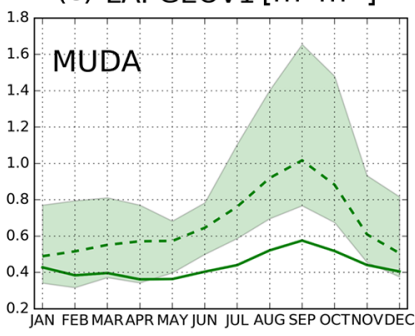

(g) SWI ASCAT [-]

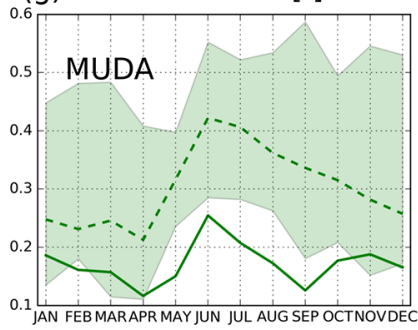

(d) LAI LDAS $\left[\mathrm{m}^{2} \mathrm{~m}^{-2}\right]$

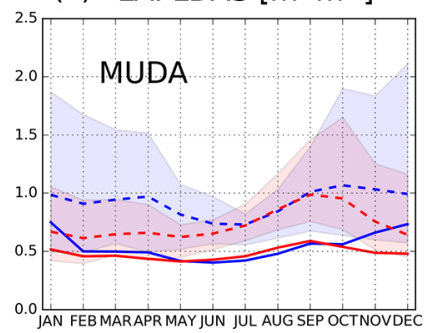

(h) $\mathrm{SSM}(1-4 \mathrm{~cm})$ LDAS $\left[\mathrm{m}^{3} \mathrm{~m}^{-3}\right]$

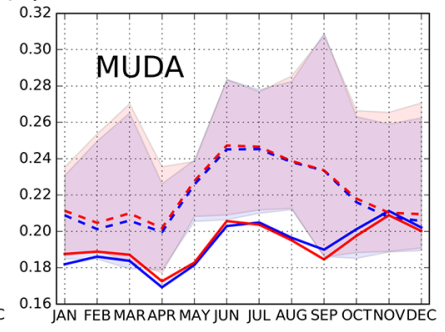

Figure 11. Upper panels represent seasonal cycles of (a) observed GEOV1 LAI from CGLS and (b) LAI from the open-loop (in blue) and the analysis (in red) for the WEUR area (see Table 1 for geographical extent). Panels (c) and (d) are similar to (a) and (b) for the MUDA area. Lower panels represent seasonal cycles of (e) ASCAT SWI from CGLS and (f) SSM from the open-loop (in blue) and the analysis (in red) for the WEUR area. Panels (g) and (h) are similar to (e) and (f) for the MUDA area. For each panel dashed line represents the average over 2010-2017 along with the minimum and maximum values; the solid lines are for the year 2018.

together with the longer memory of LAI (compared to SSM), contributes to the results presented in this sub-section. Statistical scores for LDAS_HRES open-loop and analysis are also presented, which serve as a benchmark for the forecast experiments.

Figure 12 (for WEUR) and Fig. 13 (for MUDA) upper panels illustrate the seasonal RMSD (Figs. 12a, 13a) and correlation (Figs. 12b, 13b) between LDAS_HRES SSM from the second layer of soil $(1-4 \mathrm{~cm})$ and ASCAT SSM estimates over 2017-2018. Scores are also reported for the LDAS_HRES $4 \mathrm{~d}$ (LDAS_fc4) and $8 \mathrm{~d}$ forecasts (LDAS_fc8). From the upper panels of those figures one may notice a small improvement from the analysis (solid red line) over the open-loop simulation (solid blue line), with slightly reduced RMSD values and increased correlation values. However, no improvement (or degradation) is visible from the 4 and $8 \mathrm{~d}$ forecast experiments initialized by LDAS_HRES analysis over those initialized by LDAS_HRES open-loop. As expected, LDAS_HRES SSM is closer to the observations compared with LDAS_fc4 and LDAS_fc8. It is worth pointing out that for the MUDA area there is a small positive impact of the initialization on the 4 and $8 \mathrm{~d}$ forecasts of surface soil moisture (Fig. 13a, b). These results suggest that the fast-evolving SSM model variable is more sensitive to the atmospheric forcing than to the initial conditions (at least within the forecast range presented in this study). Results for LAI are different from SSM (Figs. 12c, d and $13 \mathrm{c}, \mathrm{d})$. Firstly, there is a large improvement from the analysis (solid red line) over the open-loop (solid blue line), particularly during the LAI decaying phase (boreal and austral autumns mainly). Secondly, the LDAS_HRES open-loop (solid blue line) and the forecasts initialized by the openloop (LDAS_fc4 and LDAS_fc8) perform similarly. Furthermore, the LDAS_fc4 and LDAS_fc8 forecasts are quite consistent when initialized by the LDAS_HRES analysis. Importantly, the LDAS_HRES analysis and forecasts outperform the LDAS_HRES open-loop initial conditions and forecasts. This suggests that LAI forecasts are more sensitive to initial conditions than to the atmospheric forcing within the 4-8d range for both WEUR and MUDA regions.

These results are corroborated by Figs. 14 (for WEUR) and 15 (for MUDA) for both SSM (top) and LAI (bottom). Figures 14a and 15a show RMSD values between LDAS_HRES open-loop SSM $(1-4 \mathrm{~cm})$ and ASCAT SSM over 2017-2018 for the WEUR and MUDA domains respectively. Due to the seasonal linear rescaling applied to ASCAT estimates, the RMSD values are rather small. For the WEUR (MUDA) domain they range from 0 to $0.048 \mathrm{~m}^{3} \mathrm{~m}^{-3}$ (0 to $\left.0.040 \mathrm{~m}^{3} \mathrm{~m}^{-3}\right)$. Figures $14 \mathrm{~b}$ and $15 \mathrm{~b}$ present maps of RMSD differences between LDAS_HRES analysis (open-loop) and ASCAT SSM estimates over 2017-2018 for the WEUR and MUDA domains. Both maps are dominated by negative values (in blue) indicating that RMSD values are consistently smaller when using LDAS_HRES analysis than when us- 

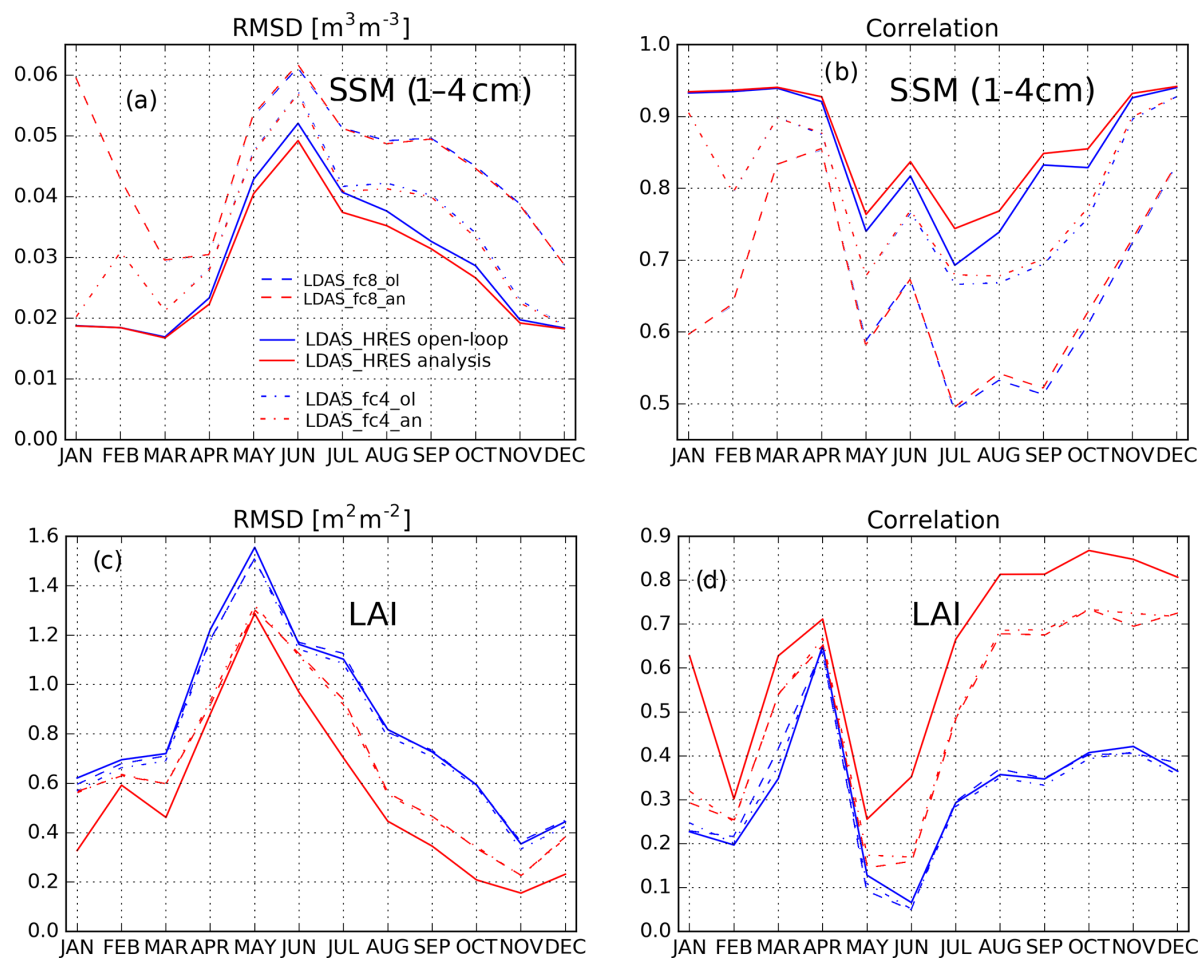

Figure 12. Seasonal (a) RMSD and (b) correlation values between soil moisture from the second layer of soil (1-4 cm) from the model forced by HRES (LDAS_HRES, open-loop in blue solid line, analysis in red solid line) and ASCAT SSM estimates over 2017-2018 over the WEUR area. Scores between SSM from the second layer of soil of LDAS_HRES, $4 \mathrm{~d}$ (dashed/dotted blue - when initialized by the open-loop - and red - when initialized by the analysis - lines) and $8 \mathrm{~d}$ (dashed blue and red lines) forecasts and ASCAT SSM estimates are also reported. Panels (c) and (d): same as (a) and (b) between modelled/analysed LAI and GEOV1 LAI estimates.
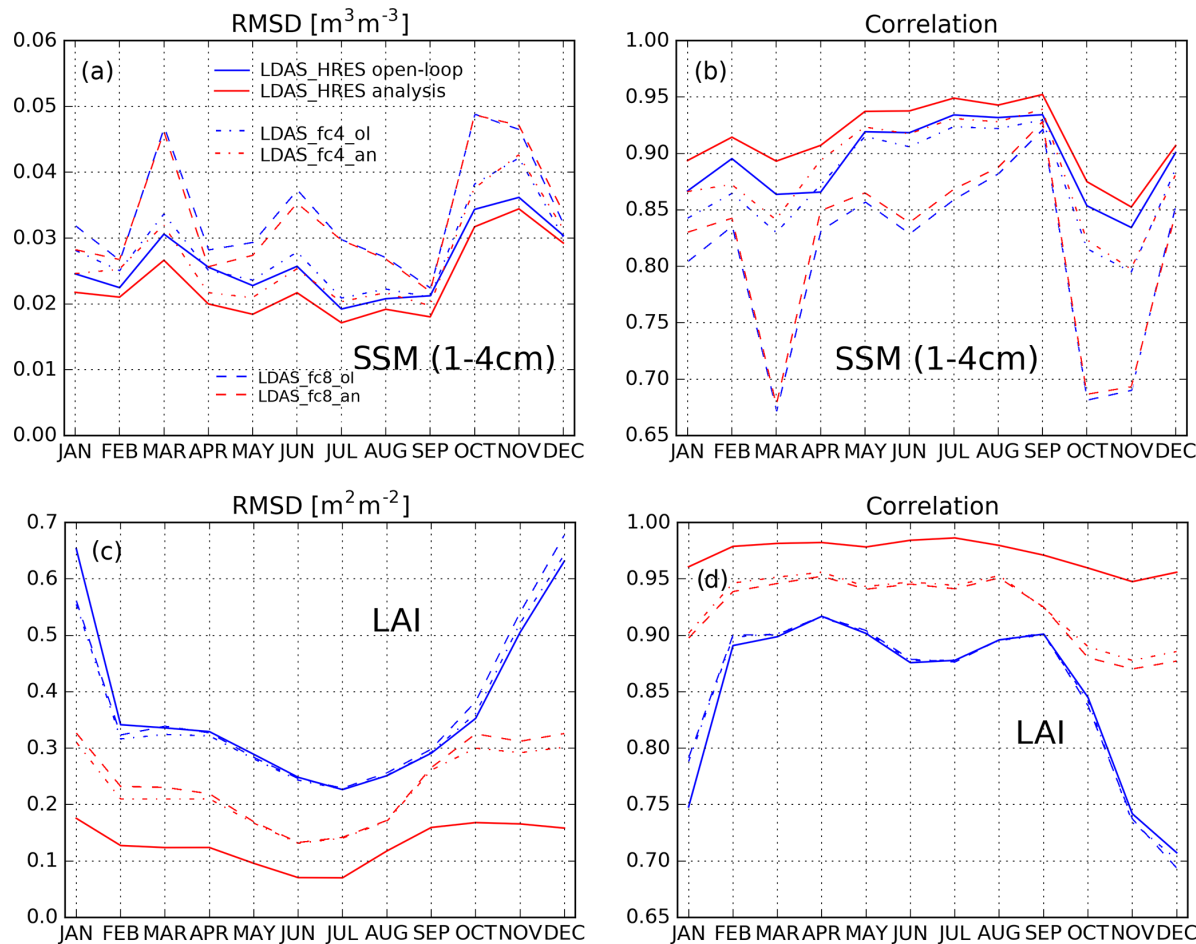

Figure 13. Same as Fig. 12 for the Murray-Darling River (MUDA) area in south-eastern Australia. 


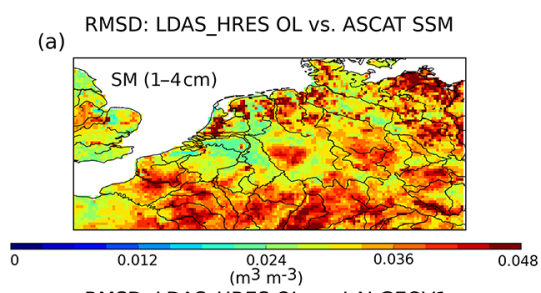

RMSD differences: (b) LDAS_HRES AN - OL

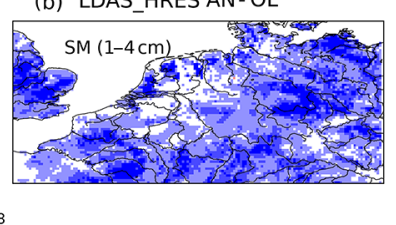

(f) LDAS_HRES AN-OL

(e)

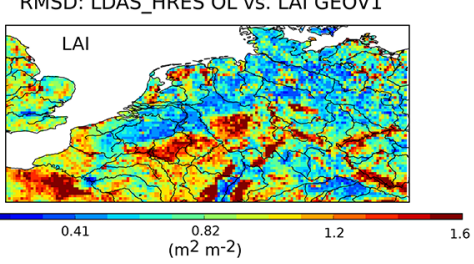

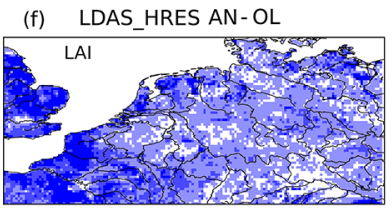

(c) LDAS_fC 4 AN - OL

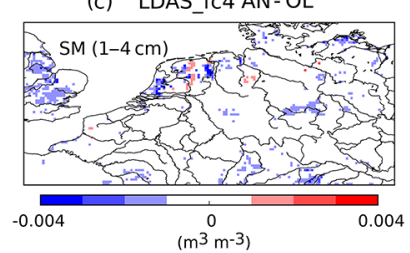

(g) LDAS_fc4 AN - OL

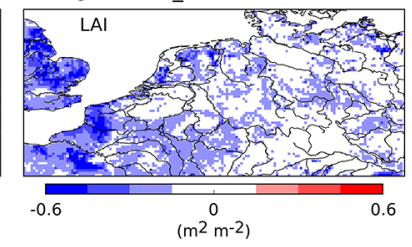

(d) LDAS fc8 AN-OL

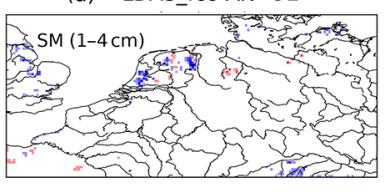

(h) LDAS_fc8 AN - OL

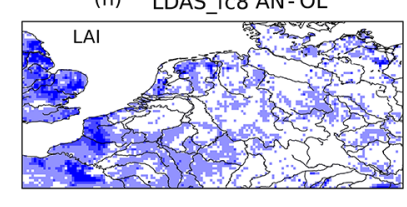

Figure 14. (a) RMSD values between LDAS_HRES open-loop and ASCAT SSM estimates over 2017-2018 for the WEUR domain; (b) RMSD differences between LDAS_HRES analysis (open-loop) and ASCAT SSM. (c), (d) and (e): same as (b) between LDAS_fc4 initialized by the analysis (open-loop) and LDAS_fc8. Bottom row: same as the top row for LAI from the different experiments and LAI GEOV1.

ing LDAS_HRES open-loop. For the MUDA domain, the RMSD values are reduced by about $15 \%$. Figures $14 \mathrm{c}$, $d$ and $15 \mathrm{c}$, $\mathrm{d}$ show maps of RMSD differences for forecast experiments (LDAS_fc4, LDAS_fc8). It appears that over both domains, the impact from the initialization is rather small. This supports previous results indicating that the forcing quality is more important than the initial conditions for the SSM forecast. However, the results for LAI support the opposite conclusion. The RMSD values for LDAS_HRES open-loop range from 0 to $1.6 \mathrm{~m}^{2} \mathrm{~m}^{-2}$ over WEUR and 0 to $1 \mathrm{~m}^{2} \mathrm{~m}^{-2}$ over MUDA (Figs. 14e and 15e). The RMSD values are reduced by up to $37 \%$ over WEUR and up to $60 \%$ over MUDA by the analysis (Figs. 14f and 15f). The enhancement from the data assimilation is consistent throughout the WEUR domain, while the improvement over the MUDA domain is concentrated in the south-eastern part (the north-western part is largely unchanged).

Similarly to Fig. 14a, b, c, d, Fig. 16 illustrates the impact of the analysis on SSM in terms of the correlation coefficient. But this time, ASCAT SWI (i.e. no rescaling) has been used for the validation. Figure 16 (top panels) shows maps of $R$ values based on the absolute values, while Fig. 16 (bottom panels) shows $R$ values based on the anomaly time series (capturing short-term variability) as defined in Albergel et al. (2018a). Figure 16a and e represent $R$ values and anomaly $R$ values for LDAS_HRES respectively. As expected, $R$ values are higher than anomaly $R$ values. Maps of differences (panels $b$ and $f$ ) of Fig. 16 suggest that after assimilation, both scores are improved almost equally. The 4 and $8 \mathrm{~d}$ forecasts still show improvements from using initial conditions from the analysis over the open-loop on $R$ values (Fig. 16c,

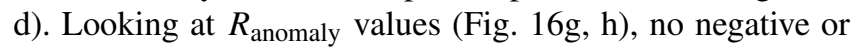
positive impact from the initial conditions can be seen.

Finally, the top panels of Fig. 17 illustrate the impact of the analysis on drainage monitoring and forecasts over WEUR. Figure 17a represents drainage from the
LDAS_HRES open-loop, with values ranging between 0 and $1 \mathrm{~kg} \mathrm{~m}^{-2} \mathrm{~d}^{-1}$. Figure $17 \mathrm{~b}$ shows the drainage difference between LDAS_HRES analysis and open-loop. The analysis impact on drainage is rather small (within $\pm 3 \%$ ) and more pronounced in areas where the analysis has largely affected LAI (see Fig. 14f, g and h). As seen in Fig. 17c and d, the forecasts are also sensitive to the initialisation in areas where the analysis effectively corrected LAI. The bottom panels of Fig. 17 illustrate a similar impact on runoff. Although we did not validate drainage and runoff in this study, previous findings suggest a neutral to positive impact of the analysis on river discharge through modifications to drainage and runoff (Albergel et al., 2017, 2018a).

\section{Discussion and conclusions}

This study has demonstrated the potential of LDAS-Monde to assimilate Earth observations (EOs) into a land surface model (LSM) to predict the impact of heatwaves and droughts on land surface conditions. LDAS-Monde is now ready for various applications, including (i) land surface reanalyses of essential climate variables (ECVs), (ii) monitoring of water resources, such as the impact of droughts on vegetation, (iii) the detection of extreme land surface conditions; and (iv) the effective initialization of LSVs for land surface forecasting. LDAS-Monde has been applied in this study to past events of 2018 with respect to a relatively short climatology (2010-2018). It is planned that it will be applied to much longer periods for future reanalysis applications. The operational application of LDASMonde near-real time could potentially improve emergency monitoring systems for LSVs. Using high-quality atmospheric reanalyses like ERA5 to force LDAS-Monde guarantees a high level of consistency since the configuration is frozen in time (no changes in spatial and vertical reso- 
(a)

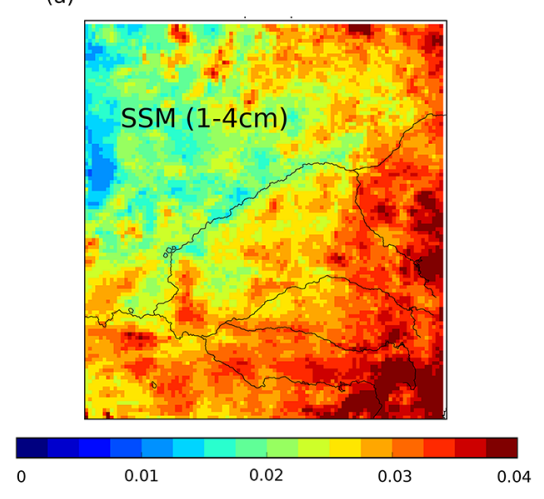

(e) RMSD: LDAS_HRES OL vs. LAI GEOV1

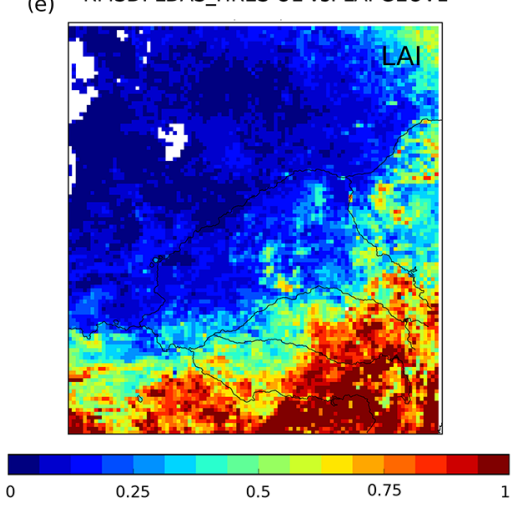

RMSD differences:

(b) LDAS HRES AN - OL

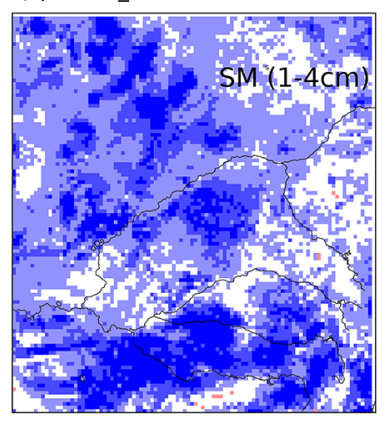

(c) LDAS fc4 AN - OL

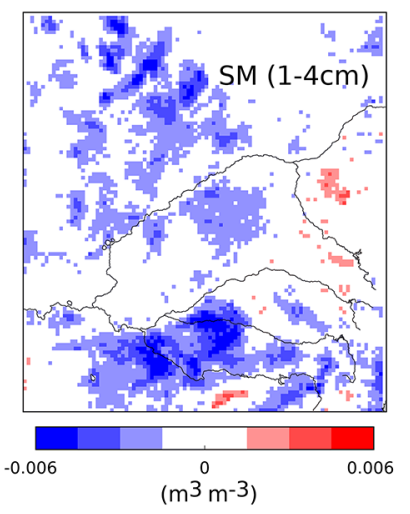

(g) LDAS_fC4 AN - OL

(f) LDAS_HRES AN - OL

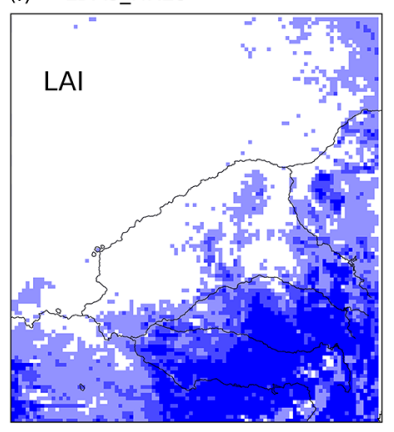

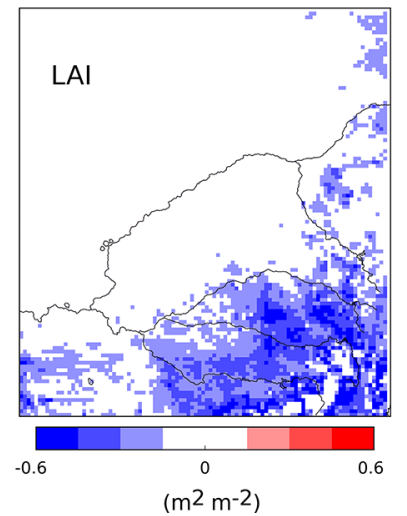

(d) LDAS fC8 AN-OL

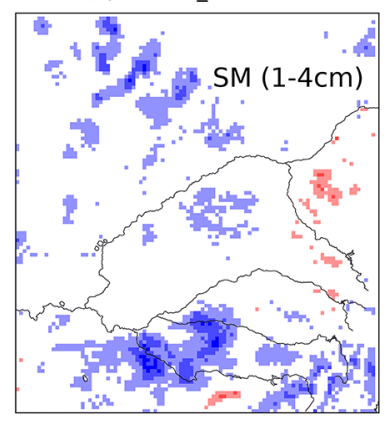

(h) LDAS fC8 AN-OL

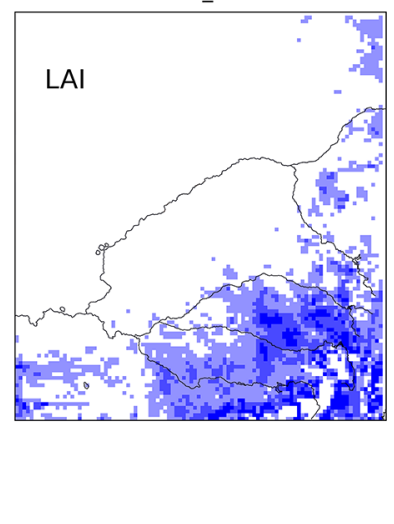

Figure 15. Same as Fig. 14 for the Murray-Darling River (MUDA) area in south-eastern Australia.
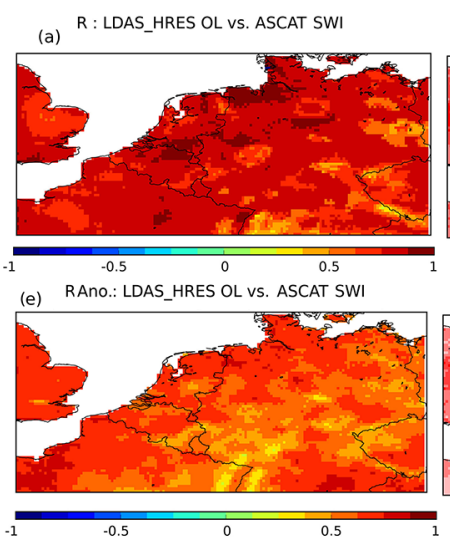

$R$ differences:
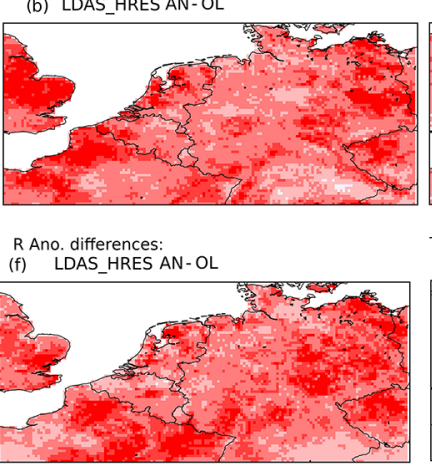

(c) LDAS fC4 AN-OL

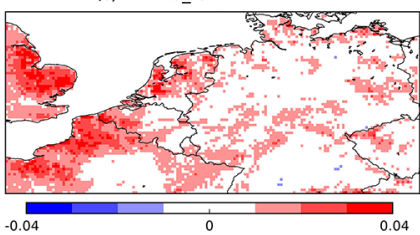

(g) LDAS fC4 AN-OL

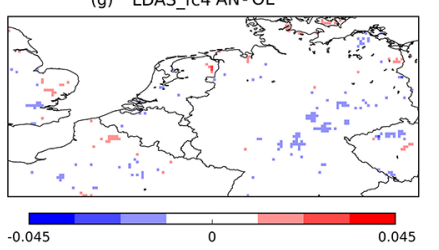

(d) LDAS fC8 AN-OL

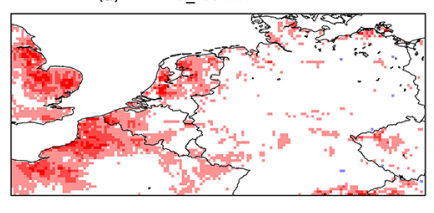

(h) LDAS_fC8 AN-OL

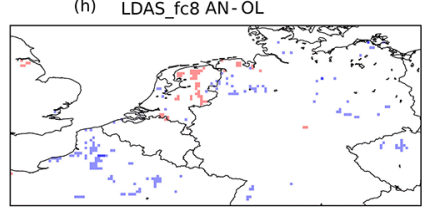

Figure 16. (a) $R$ values between LDAS_HRES open-loop and ASCAT SWI estimates over 2017-2018 for the WEUR domain; (b) $R$ differences between LDAS_HRES analysis (open-loop) and ASCAT SWI. (c) and (d): same as (b) between LDAS_fc4 initialized by the analysis (open-loop) and LDAS_fc8. Bottom row: same as top row for $R$ values based on anomaly time series.

lutions, data assimilation or parameterizations). The coarse spatial resolution of ERA5 makes it affordable to run long time periods and large-scale LDAS-Monde experiments. With ERA5 available from 1979 and now covering nearreal-time needs with its ERA5T version (https://climate. copernicus.eu/climate-reanalysis, last access: August 2020), an LDAS_ERA5 configuration would be able to provide a long-term climatology as well as near-real-time anomaly detections of the land surface conditions at coarse resolution $\left(0.25^{\circ}\right)$. Significant anomalies could then be used to trigger more focused "on-demand" simulations for regions experiencing extreme conditions. For these simulations, LDAS- 

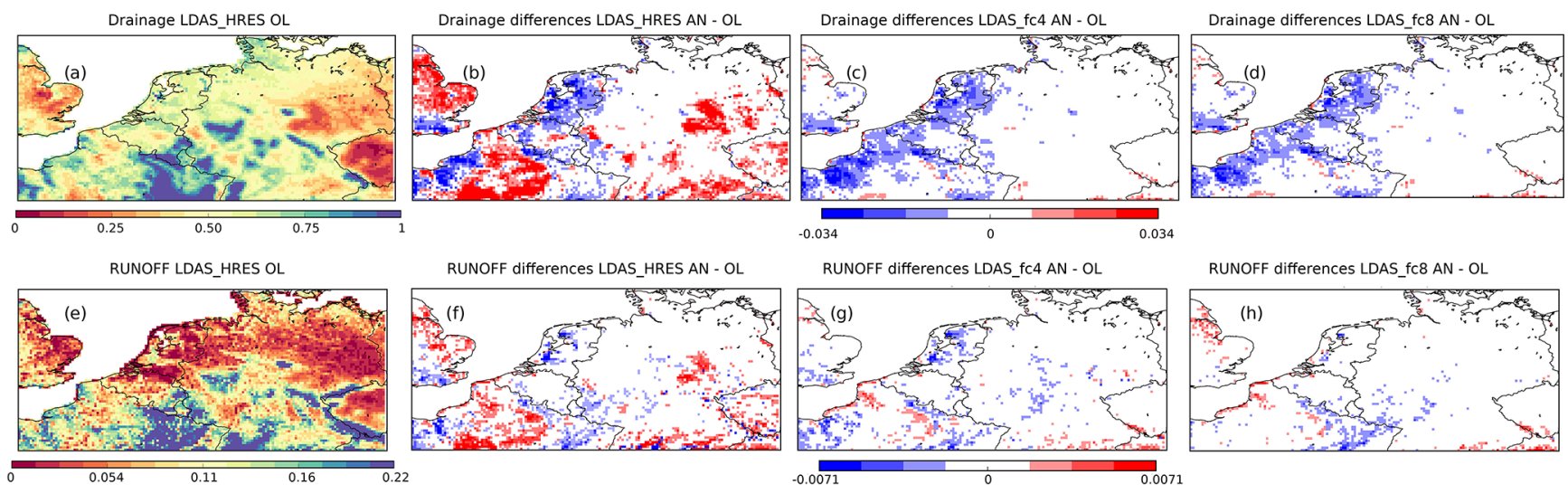

RUNOFF differences LDAS_fC4 AN - OL

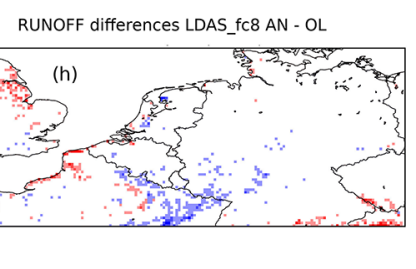

Figure 17. (a) Drainage values for LDAS_HRES open-loop over 2017-2018 for the WEUR domain; (b) drainage differences between LDAS_HRES analysis and open-loop. (c) and (d): same as (b) between LDAS_fc4 initialized by the analysis and LDAS_fc4 initialized by the open-loop and between LDAS_fc8 initialized by the analysis and LDAS_fc8 initialized by the open-loop. Bottom row: same as the top row for runoff. Units are $\mathrm{kg} \mathrm{m}^{-2} \mathrm{~d}^{-1}$.

Monde could be run at higher resolution by forcing the LSM with an enhanced resolution forecast in order to provide more information, such as the ECMWF operational highresolution product $\left(0.10^{\circ}\right)$. The capability of such an approach was illustrated in our study for two regions in northwestern Europe and south-eastern Australia. In terms of the RMSD, our results showed a very small impact of initial conditions on the forecasts of SSM. This was expected due to the short-term memory of the surface soil layer, which is dominated by the antecedent meteorological forcing. However, the LAI initialization had significant impact on the LAI forecast skill. This was also expected due to the long-term memory of vegetation evolution. For SSM, the assimilation is performed after a rescaling of the observations to the model climatology (see Sect. 2.3), which ensures that the model and observations are unbiased with respect to each other. However, LAI is not bias-corrected, which allows the assimilation process to remove bias in the modelled LAI (with respect to the observation). This technical difference between SSM and LAI assimilation, combined with the longer memory of LAI compared to SSM, contributes to the results presented in this study. Despite the expected behaviour of these two LSVs in forecasting, our results show that the LDAS-Monde system is capable of propagating the initial LAI conditions, which is relevant for LSV medium-range forecasting and potentially for longer lead times, such as seasonal forecasts. The strong impact of LAI initialization on the forecast does not seem to propagate to the surface soil moisture, and further studies are necessary to test the impact of initial conditions on other variables from LDAS-Monde (including soil moisture in deeper layers and evapotranspiration). Another possibility would be to force LDAS-Monde using the 51-member ECMWF ensemble forecasts. Although the ensemble system has coarser spatial resolution $\left(\sim 0.20^{\circ}\right)$ than the deterministic forecast, it accounts for forcing uncertainty in the LSVs through the en- semble spread and extends to a $15 \mathrm{~d}$ lead time. The maximum range of the soil and vegetation forecasts could even be extended to 6 months if seasonal atmospheric forecasts were used as forcing.

LDAS-Monde has some limitations, where future developments are needed to improve the representation of LSVs. For instance, it does not consider snow data assimilation yet. It has been shown in this study that if the snow accumulation seems to be represented correctly in the system, the onset of snowmelt is too early in the spring. To overcome this issue, two possibilities will be explored. Firstly, a recently developed ISBA parametrization, MEB (Multiple Energy Budget), is known to lead to a better representation of the snowpack (Boone et al., 2017). This could be particularly useful in the densely forested areas of the Northern Hemisphere, where large differences between LDAS-Monde and the IMS snow cover were found in spring (Fig. S2i, Aaron Boone CNRM, personal communication, June 2019). Another enhancement of LDAS-Monde will be to adapt the current data assimilation scheme to permit the assimilation the IMS snow-cover data, which is implemented at NWP centres such as the ECMWF (de Rosnay et al., 2014). The current SEKF data assimilation scheme is also being revisited. Even though it has provided good results, one of its limitations is the computational cost of the Jacobian matrix, which needs one model run for each control variable. As the number of control variables is expected to increase, this approach would require significant computational resources. Therefore, more flexible ensemble-based data assimilation approaches have recently been implemented in LDAS-Monde, such as the ensemble square root filter (EnSRF, Fairbain et al., 2015; Bonan et al., 2020). Bonan et al. (2020) have evaluated performances from the EnSRF and the SEKF over the Euro-Mediterranean area. Both data assimilation schemes have a similar behaviour for LAI while for SSM, the EnSRF estimates tend to be closer 
to observations than those from the SEKF. They have also conducted an independent evaluation of both assimilation approaches using satellite estimates of evapotranspiration and GPP together with river discharge observations from gauging stations. They have found that the EnSRF gives a systematic (moderate) improvement for evapotranspiration and GPP and a highly positive impact on river discharges, while the SEKF leads to more contrasting performance. As for applications in hydrology, the $0.5^{\circ}$ spatial resolution TRIP river network is currently being improved to $1 / 12^{\circ}$ globally.

CNRM is also investigating the direct assimilation of ASCAT radar backscatter (Shamambo et al., 2019). This has the potential to improve the way vegetation is accounted for in the change detection approach used to retrieve SSM with an improved representation of its effect. Assimilating ASCAT radar backscatter also raises the question of how to properly specify SSM observation, background, and model error covariance matrices, which are currently based on soil properties (see Sect. 2.1.3 on data assimilation). The last decade has seen the development of techniques to estimate those matrices. Approaches based on Desroziers diagnostics (Desroziers et al., 2005) are computationally affordable for land data assimilation systems and could provide insightful information on the various sources of the data assimilation system.

Furthermore, a comparison of LDAS-Monde with existing datasets from other centres needs to be considered. Current work at Météo-France has began to compare its quality against state-of-the-art reanalyses such as those from NASA at both the global scale (GLDAS, Rodell et al., 2004, MERRA-2, Reichle et al., 2017; Draper et al., 2018) and regional scale (NCALDAS over the continental USA, FLDAS over Africa). Finally, first work has begun to run LDASMonde at kilometric- and sub-kilometric-scale spatial resolutions. Promising results have been obtained by assimilating SSM and LAI over the AROME domain (Applications de la Recherche à l'Opérationnel à Méso-Echelle, https://www. umr-cnrm.fr/spip.php?article120, last access: July 2019) of Météo-France.

Code availability. LDAS-Monde is a part of the ISBA land surface model and is available as open source via the surface modelling platform called SURFEX. SURFEX can be downloaded freely at http://www.umr-cnrm.fr/surfex/ (CNRM, 2016) using a CECILLC Licence (a French equivalent to the L-GPL licence; http:// cecill.info/licences/Licence_CeCILL_V1.1-US.html, CEA-CNRSInria, 2013). It is updated at a relatively low frequency (every 3 to 6 months). If more frequent updates are needed or if what is required is not in Open-SURFEX (DrHOOK, FA/LFI formats, GAUSSIAN grid), you are invited to follow the procedure to get a SVN account and to access real-time modifications of the code (see the instructions at the first link). The developments presented in this study stemmed from SURFEX version 8.1. LDAS-Monde technical documentation and contact points are freely available at https://opensource.umr-cnrm.fr/ projects/openldasmonde/files (CNRM, 2019).
Data availability. Data used in this paper are available upon request by contacting the corresponding author.

Supplement. The supplement related to this article is available online at: https://doi.org/10.5194/hess-24-4291-2020-supplement.

Author contributions. CA and JCC conceptualized the project. CA led the investigation, determined the methodology and wrote the original draft of the paper together with YZ, BB, SM and NRF. All the co-authors contributed to the review and editing of the paper.

Competing interests. The authors declare that they have no conflict of interest.

Acknowledgements. Results were generated using the Copernicus Climate Change Service Information, 2017. The authors would like to thank the Copernicus Global Land Service for providing the satellite-derived leaf area index and surface soil moisture.

Financial support. This research has been supported by the RT Antoine de Saint-Exupéry Foundation (POMME-V project, grant no. CDT-R056-L00-T00) and the Climate Change Initiative Programme Extension, Phase 1 - Climate Modeling User Group ESA (grant no. 4000125156/18/I-NB).

Review statement. This paper was edited by Harrie-Jan Hendricks Franssen and reviewed by four anonymous referees.

\section{References}

Albergel, C., Rüdiger, C., Pellarin, T., Calvet, J.-C., Fritz, N., Froissard, F., Suquia, D., Petitpa, A., Piguet, B., and Martin, E.: From near-surface to root-zone soil moisture using an exponential filter: an assessment of the method based on in-situ observations and model simulations, Hydrol. Earth Syst. Sci., 12, 1323-1337, https://doi.org/10.5194/hess-12-1323-2008, 2008.

Albergel, C., Munier, S., Leroux, D. J., Dewaele, H., Fairbairn, D., Barbu, A. L., Gelati, E., Dorigo, W., Faroux, S., Meurey, C., Le Moigne, P., Decharme, B., Mahfouf, J.-F., and Calvet, J.-C.: Sequential assimilation of satellite-derived vegetation and soil moisture products using SURFEX_v8.0: LDAS-Monde assessment over the Euro-Mediterranean area, Geosci. Model Dev., 10, 3889-3912, https://doi.org/10.5194/gmd-10-3889-2017, 2017.

Albergel, C., Munier, S., Bocher, A., Bonan, B., Zheng, Y., Draper, C., Leroux, D. J., and Calvet, J.-C.: LDAS-Monde Sequential Assimilation of Satellite Derived Observations Applied to the Contiguous US: An ERA5 Driven Reanalysis of the Land Surface Variables, Remote Sens., 10, 1627, https://doi.org/10.3390/rs10101627, 2018a.

Albergel, C., Dutra, E., Munier, S., Calvet, J.-C., Munoz-Sabater, J., de Rosnay, P., and Balsamo, G.: ERA-5 and ERA-Interim 
driven ISBA land surface model simulations: which one performs better?, Hydrol. Earth Syst. Sci., 22, 3515-3532, https://doi.org/10.5194/hess-22-3515-2018, 2018 b.

Albergel, C., Dutra, E., Bonan, B., Zheng, Y., Munier, S., Balsamo, G., de Rosnay, P., Muñoz-Sabater, J., and Calvet, J.-C.: Monitoring and Forecasting the Impact of the 2018 Summer Heatwave on Vegetation, Remote Sens., 11, 520, https://doi.org/10.3390/rs11050520, 2019.

Balsamo, G., Albergel, C., Beljaars, A., Boussetta, S., Brun, E., Cloke, H., Dee, D., Dutra, E., Muñoz-Sabater, J., Pappenberger, F., de Rosnay, P., Stockdale, T., and Vitart, F.: ERAInterim/Land: a global land surface reanalysis data set, Hydrol. Earth Syst. Sci., 19, 389-407, https://doi.org/10.5194/hess-19389-2015, 2015.

Balsamo, G., Agusti-Panareda, A., Albergel, C., Arduini, G., Beljaars, A., Bidlot, J., Bousserez, N., Boussetta, S., Brown, A., Buizza, R., Buontempo, C., Chevallier, F., Choulga, M., Cloke, H., Cronin, M. F., Dahoui, M., De Rosnay, P., Dirmeyer, P. A., Dutra, M. D. E., Ek, M. B., Gentine, P., Hewitt, H., Keeley, S. P. E., Kerr, Y., Kumar, S., Lupu, C., Mahfouf, J.-F., McNorton, J., Mecklenburg, S., Mogensen, K., Muñoz-Sabater, J., Orth, R., Rabier, F., Reichle, R., Ruston, B., Pappenberger, F., Sandu, I., Seneviratne, S. I., Tietsche, S., Trigo, I. F., Uijlenhoet, R., Wedi, N., Woolway, R. I., and Zeng, X.: Satellite and In Situ Observations for Advancing Global Earth Surface Modelling: A Review, Remote Sens., 10, 2038, https://doi.org/10.3390/rs10122038, 2018.

Bamzai, A. and Shukla, J.: Relation between Eurasian snow cover, snow depth and the Indian summer monsoon: An observational study, J. Climate, 12, 3117-3132, 1999.

Barbu, A. L., Calvet, J.-C., Mahfouf, J.-F., Albergel, C., and Lafont, S.: Assimilation of Soil Wetness Index and Leaf Area Index into the ISBA-A-gs land surface model: grassland case study, Biogeosciences, 8, 1971-1986, https://doi.org/10.5194/bg-8-19712011, 2011.

Barbu, A. L., Calvet, J.-C., Mahfouf, J.-F., and Lafont, S.: Integrating ASCAT surface soil moisture and GEOV1 leaf area index into the SURFEX modelling platform: a land data assimilation application over France, Hydrol. Earth Syst. Sci., 18, 173-192, https://doi.org/10.5194/hess-18-173-2014, 2014.

Barella-Ortiz, A. and Quintana-Seguí, P.: Evaluation of drought representation and propagation in regional climate model simulations across Spain, Hydrol. Earth Syst. Sci., 23, 5111-5131, https://doi.org/10.5194/hess-23-5111-2019, 2019.

Baret, F., Weiss, M., Lacaze, R., Camacho, F., Makhmarad, H., Pacholczyk, P., and Smetse, B.: GEOV1: LAI, FAPAR essential climate variables and FCOVER global time series capitalizing over existing products, Part 1: Principles of development and production, Remote Sens. Environ., 137, 299-309, https://doi.org/10.1016/j.rse.2012.12.027, 2013.

Bartalis, Z., Wagner, W., Naeimi, V., Hasenauer, S., Scipal, K., Bonekamp, H., Figa, J., and Anderson, C.: Initial soil moisture retrievals from the METOP-A advanced Scatterometer (ASCAT), Geophys. Res. Lett., 34, L20401, https://doi.org/10.1029/2007GL031088, 2007.

Bauer, P., Thorpe, A., and Brunet, G.: The quiet revolution of numerical weather prediction, Nature, 525, 47-55, https://doi.org/10.1038/nature14956, 2015.
Beck, H. E., Pan, M., Roy, T., Weedon, G. P., Pappenberger, F., van Dijk, A. I. J. M., Huffman, G. J., Adler, R. F., and Wood, E. F.: Daily evaluation of 26 precipitation datasets using Stage-IV gauge-radar data for the CONUS, Hydrol. Earth Syst. Sci., 23, 207-224, https://doi.org/10.5194/hess-23-207-2019, 2019.

Bell, J. E., Palecki, M. A., Baker, C. B., Collins, W. G., Lawrimore, J. H., Leeper, R. D., Hall, M. E., Kochendorfer, J., Meyers, T. P., Wilson, T., and Diamond, H. J.: U.S. Climate Reference Network soil moisture and temperature observations, J. Hydrometeorol., 14, 977-988, https://doi.org/10.1175/JHM-D-12-0146.1, 2013.

Bierkens, M. and van Beek, L.: Seasonal predictability of European discharge: Nao and hydrological response time, J. Hydrometeorol., 10, 953-968, 2009.

Blyverket, J., Hamer, P. D., Schneider, P., Albergel, C., and Lahoz, W. A.: Monitoring Soil Moisture Drought over Northern High Latitudes from Space, Remote Sens., 11, 1200, https://doi.org/10.3390/rs11101200, 2019.

Bonan, B., Albergel, C., Zheng, Y., Barbu, A. L., Fairbairn, D., Munier, S., and Calvet, J.-C.: An ensemble square root filter for the joint assimilation of surface soil moisture and leaf area index within the Land Data Assimilation System LDASMonde: application over the Euro-Mediterranean region, Hydrol. Earth Syst. Sci., 24, 325-347, https://doi.org/10.5194/hess-24325-2020, 2020.

Boone, A. and Etchevers, P.: An intercomparison of three snow schemes of varying complexity coupled to the same land-surface model: local scale evaluation at an Alpine site, J. Hydrometeorol., 2, 374-394, 2001.

Boone, A., Masson, V., Meyers, T., and Noilhan, J.: The influence of the inclusion of soil freezing on simulations by a soil-vegetationatmosphere transfer scheme, J. Appl. Meteorol., 39, 1544-1569, 2000.

Boone, A., Samuelsson, P., Gollvik, S., Napoly, A., Jarlan, L., Brun, E., and Decharme, B.: The interactions between soil-biosphereatmosphere land surface model with a multi-energy balance (ISBA-MEB) option in SURFEXv8 - Part 1: Model description, Geosci. Model Dev., 10, 843-872, https://doi.org/10.5194/gmd10-843-2017, 2017.

Bruce, J. P.: Natural disaster reduction and global change, B. Am. Meteorol. Soc., 75, 1831-1835, 1994.

Bureau of Meteorology Special Climate Statement 70: Drought conditions in eastern Australia and impact on water resources in the Murray-Darling Basin, issued 9 April 2019, available at: http://www.bom.gov.au/climate/current/statements/scs70.pdf (last access: August 2020), 2019.

Calvet, J.-C., Noilhan, J., Roujean, J.-L., Bessemoulin, P., Cabelguenne, M., Olioso, A., and Wigneron, J.-P.: An interactive vegetation SVAT model tested against data from six 780 contrasting sites, Agric. For. Meteorol, 92, 73-95, 1998.

Calvet, J.-C., Rivalland, V., Picon-Cochard, C., and Guehl, J.-M.: Modelling forest transpiration and $\mathrm{CO}_{2}$ fluxes - Response to soil moisture stress, Agric. For. Meteorol, 124, 143-156, 2004.

CEA-CNRS-Inria: http://cecill.info/licences/Licence_CeCILL_V1. 1-US.html (last access: August 2020), 2013.

CNRM: http://www.umr-cnrm.fr/surfex/ (last access: August 2020), 2016.

CNRM: LDAS-Monde technical documentation and contact points, https://opensource.umr-cnrm.fr/projects/openldasmonde/ files (last access: August 2020), 2019. 
Cook, E. R., Seager, R., Cane, M. A., and Stahle, D. W.: North American drought: reconstructions, causes, and consequences, Earth Sci. Rev., 81, 93-134, 2007.

Decharme, B., Boone, A., Delire, C., and Noilhan, J.: Local evaluation of the Interaction between soil biosphere atmosphere soil multilayer diffusion scheme using four pedotransfer functions, J. Geophys. Res., 116, D20126, https://doi.org/10.1029/2011JD016002, 2011.

Decharme, B., Martin, E., and Faroux, S.: Reconciling soil thermal and hydrological lower boundary conditions in land surface models, J. Geophys. Res.-Atmos., 118, 7819-7834, 2013.

Decharme, B., Brun, E., Boone, A., Delire, C., Le Moigne, P., and Morin, S.: Impacts of snow and organic soils parameterization on northern Eurasian soil temperature profiles simulated by the ISBA land surface model, The Cryosphere, 10, 853-877, https://doi.org/10.5194/tc-10-853-2016, 2016.

Decharme, B., Delire, C., Minvielle, M., Colin, J., Vergnes, J.-P., Alias, A., Saint-Martin, D., Séférian, R., Sénési, S., and Voldoire, A.: Recent changes in the ISBA-CTRIP Land Surface System for use in the CNRM-CM6 climate model and in global off-line hydrological applications, J. Adv. Model Earth Sy., 11, 12071252, https://doi.org/10.1029/2018MS001545, 2019.

Dee, D. P., Uppala, S. M., Simmons, A. J., Berrisford, P., Poli, P., Kobayashi, S., Andrae, U., Balmaseda, M. A., Balsamo, G., and Bauer, D. P.: The ERA-Interim reanalysis: Configuration and performance of the data assimilation system, Q. J. Roy. Meteor. Soc., 137, 553-597, 2011.

de Jeu, R. A., Wagner, W., Holmes, T. R. H., Dolman, A. J., Van De Giesen, N. C., and Friesen, J.: Global soil moisture patterns observed by space borne microwave radiometers and scatterometers, Surv. Geophys., 29, 399-420, 2008.

de Rosnay, P. A.: simplified Extended Kalman Filter for the global operational soil moisture analysis at ECMWF, Q. J. Roy. Meteor. Soc., 139, 1199-1213, https://doi.org/10.1002/qj.2023, 2013.

de Rosnay, P., Balsamo, G., Albergel, C., Muñoz-Sabater, J., and Isaksen, L.: Initialisation of land surface variables for numerical weather prediction, Surv. Geophys., 35, 607-621, https://doi.org/10.1007/s10712-012-9207-x, 2014.

Desroziers, G., Berre, L., Chapnik, B., and Poli, P.: Diagnosis of observation, background and analysis-error statistics in observation space, Q. J. Roy. Meteor. Soc., 131, 3385-3396, 2005.

Di Napoli, C., Pappenberger, F., and Cloke, H. L.: Verification of Heat Stress Thresholds for a Health-Based HeatWave Definition, J. Appl. Meteor. Climatol., 58, 1177-1194, https://doi.org/10.1175/JAMC-D-18-0246.1, 2019.

Dirmeyer, P. A., Gao, X., Zhao, M., Guo, Z., Oki, T., and Hanasaki, N.: The Second Global Soil Wetness Project (GSWP2): Multi-model analysis and implications for our perception of the land surface, B. Am. Meteorol. Soc., 87, 1381-1397, https://doi.org/10.1175/BAMS-87-10-1381, 2006.

Dorigo, W. A., Wagner, W., Hohensinn, R., Hahn, S., Paulik, C., Xaver, A., Gruber, A., Drusch, M., Mecklenburg, S., van Oevelen, P., Robock, A., and Jackson, T.: The International Soil Moisture Network: a data hosting facility for global in situ soil moisture measurements, Hydrol. Earth Syst. Sci., 15, 1675-1698, https://doi.org/10.5194/hess-15-1675-2011, 2011.

Dorigo, W. A., Gruber, A., De Jeu, R. A. M., Wagner, W., Stacke, T., Loew, A., Albergel, C., Brocca, L., Chung, D., Parinussa, R. M., and Kidd, R.: Evaluation of the ESA CCI soil moisture product using ground-based observations, Remote Sens. Environ., 162, 380-395, https://doi.org/10.1016/j.rse.2014.07.023, 2015.

Draper, C. S., Mahfouf, J.-F., and Walker, J. P.: An EKF assimilation of AMSR-E soil moisture into the ISBA land surface scheme, J. Geophys. Res., 114, D20104, https://doi.org/10.1029/2008JD011650, 2009.

Draper, C., Mahfouf, J.-F., Calvet, J.-C., Martin, E., and Wagner, W.: Assimilation of ASCAT near-surface soil moisture into the SIM hydrological model over France, Hydrol. Earth Syst. Sci., 15, 3829-3841, https://doi.org/10.5194/hess-15-3829-2011, 2011.

Draper, C. S., Reichle, R. H., and Koster, R. D.: Assessment of MERRA-2 Land Surface Energy Flux Estimates, J. Climate, 31, 671-691, https://doi.org/10.1175/JCLI-D-17-0121.1, 2018.

Fairbairn, D., Barbu, A. L., Mahfouf, J.-F., Calvet, J.-C., and Gelati, E.: Comparing the ensemble and extended Kalman filters for in situ soil moisture assimilation with contrasting conditions, Hydrol. Earth Syst. Sci., 19, 4811-4830, https://doi.org/10.5194/hess-19-4811-2015, 2015.

Fairbairn, D., Barbu, A. L., Napoly, A., Albergel, C., Mahfouf, J.F., and Calvet, J.-C.: The effect of satellite-derived surface soil moisture and leaf area index land data assimilation on streamflow simulations over France, Hydrol. Earth Syst. Sci., 21, 20152033, https://doi.org/10.5194/hess-21-2015-2017, 2017.

Faroux, S., Kaptué Tchuenté, A. T., Roujean, J.-L., Masson, V., Martin, E., and Le Moigne, P.: ECOCLIMAP-II/Europe: a twofold database of ecosystems and surface parameters at $1 \mathrm{~km}$ resolution based on satellite information for use in land surface, meteorological and climate models, Geosci. Model Dev., 6, 563582, https://doi.org/10.5194/gmd-6-563-2013, 2013.

Fox, A. M., Hoar, T. J., Anderson, J. L., Arellano, A. F., Smith, W. K., Litvak, M. E., MacBean, N., Schimel, D. S., and Moore, D. J. P.: Evaluation of a Data Assimilation System for Land Surface Models using CLM4.5, J. Adv. Model. Earth Syst., 10, 247124942, 2018.

Gibelin, A.-L., Calvet, J.-C., Roujean, J.-L., Jarlan, L., and Los, S. O.: Ability of the land surface model ISBA-A-gs to simulate leaf area index at global scale: Comparison with satellite products, J. Geophys. Res., 111, 1-16, 2006.

Gruber, A., Su, C.-H., Zwieback, S., Crow, W., Dorigo, W., and Wagner, W.: Recent advances in (soil moisture) triple collocation analysis, Int. J. Appl. Earth Obs. Geoinf., 45, 200-211, 2016.

Hersbach, H., de Rosnay, P. Bell, B., Schepers, D., Simmons, S., Soci, S., Abdalla, S., Alonso Balmaseda, M., Balsamo, G., Bechtold, P., Berrisford, P., Bidlot, J., de Boisséson, E., Bonavita, M., Browne, P., Buizza, R., Dahlgren, P., Dee, D., Dragani, R., Diamantakis, M., Flemming, J., Forbes, R., Geer, A., Haiden, T., Hólm, E., Haimberger, L., Hogan, R., Horányi, A., Janisková, M., Laloyaux, P., Lopez, P., Muñoz-Sabater, J., Peubey, C., Radu, R., Richardson, D., Thépaut, J.-N., Vitart, F., Yang, X., Zsótér, E., and Zuo, H.: Operational global reanalysis: Progress, future directions and synergies with NWP, ERA Rep. Ser., 27, 65, https://doi.org/10.21957/tkic6g3wm, 2018.

Hersbach, H., Bell, B., Berrisford, P., Hirahara, S., Horanyi, A., Muñoz-Sabater, J., Nicolas, J., Peubey, C., Radu, R., Schepers, D., Simmons, A., Soci, C., Abdalla, S., Abellan, X., Balsamo, G., Bechtold, P., Biavati, G., Bidlot, J., Bonavita, M., De Chiara, G., Dahlgren, P., Dee, D., Diamantakis, M., Dragani, R., Flemming, J., Forbes, R., Fuentes, M., Geer, A., Haim- 
berger, L., Healy, S., Hogan, R. J., Holm, E., Janiskova, M., Keeley, S., Laloyaux, P., Lopez, P., Radnoti, G., de Rosnay, P., Rozum, I., Vamborg, F., Villaume, S., and Thépaut, J.-N.: The ERA5 global reanalysis, Q. J. Roy. Meteor. Soc., 146, 19992049, https://doi.org/10.1002/qj.3803, 2020.

Ionita, M., Tallaksen, L. M., Kingston, D. G., Stagge, J. H., Laaha, G., Van Lanen, H. A. J., Scholz, P., Chelcea, S. M., and Haslinger, K.: The European 2015 drought from a climatological perspective, Hydrol. Earth Syst. Sci., 21, 1397-1419, https://doi.org/10.5194/hess-21-1397-2017, 2017.

IPCC: Managing the Risks of Extreme Events and Disasters to Advance Climate Change Adaptation. A Special Report of Working Groups I and II of the Intergovernmental Panel on Climate Change, Cambridge University Press, Cambridge, UK, New York, New York, USA, 582 pp., 2012.

IPCC: Climate change 2014: Synthesis Report. Contribution of Working Groups I, II and III to the Fifth Assessment Report of the Intergovernmental Panel on Climate Change, edited by: Core Writing Team, Pachauri, R. K., and Meyer, L. A., IPCC, Geneva, Switzerland, 151 pp., 2014.

Jacobs, C. M. J., van den Hurk, B. J. J. M., and de Bruin, H. A. R.: Stomatal behaviour and photosynthetic rate of unstressed grapevines in semi-arid conditions, Agric. For. Meteorol., 80, 111-134, 1996.

Jarlan, L., Balsamo, G., Lafont, S., Beljaars, A., Calvet, J.-C., and Mougin, E.: Analysis of leaf area index in the ECMWF land surface model and impact on latent heat on carbon fluxes: Application to West Africa, J. Geophys. Res., 113, D24117, https://doi.org/10.1029/2007JD009370, 2008.

Joiner, J., Yoshida, Y., Guanter, L., and Middleton, E. M.: New methods for the retrieval of chlorophyll red fluorescence from hyperspectral satellite instruments: simulations and application to GOME-2 and SCIAMACHY, Atmos. Meas. Tech., 9, 39393967, https://doi.org/10.5194/amt-9-3939-2016, 2016.

Jung, M., Reichstein, M., Schwalm, C. R., Huntingford, C., Sitch, S., Ahlström, A., Arneth, A., Camps-Valls, G., Ciais, P., Friedlingstein, P., Gans, F., Ichii, K., Jain, A. K., Kato, E., Papale, D., Poulter, B., Raduly, B., Rödenbeck, C., Tramontana, G., Viovy, N., Wang, Y.-P., Weber, U., Zaehle, S., and Zeng, N.: Compensatory water effects link yearly global land $\mathrm{CO}_{2}$ sink changes to temperature, Nature, 541, 516-520, https://doi.org/10.1038/nature20780, 2017.

Kaminski, T., Knorr, W., Rayner, P. J., and Heimann, M., Assimilating atmospheric data into a terrestrial biosphere model: A case study of the seasonal cycle, Global Biogeochem. Cycles, 16, 1066, https://doi.org/10.1029/2001GB001463, 2002.

Kidd, R., Makhmara, H., and Paulik, C.: GIO GL1 PUM SWI I1.00.pdf., p. 25, available at: http://land.copernicus.eu/global/ products/SWI/Documents/ProductUserManual (last access: 1 June 2019), 2013.

Koster, R. D., Mahanama, S. P. P., Livneh, B., Lettenmaier, D. P., and Reichle, R. H.: Skill in stremflow forecasts derived from large-scale estimates of soil moisture and snow, Nat. Geosci. Lett., 3, 613-616, 2010.

Kumar, S. V., Zaitchik, B. F., Peters-Lidard, C. D., Rodell, M., Reichle, R., Li, B., Jasinski, M., Mocko, D., Getirana, A., De Lannoy, G., Cosh, M. H., Hain, C. R., Anderson, M., Arsenault, K. R., Xia, Y., and Ek, M.: Assimilation of Gridded GRACE Terrestrial Water Storage Estimates in the North American Land
Data Assimilation System, J. Hydrometeorol., 17, 1951-1972, https://doi.org/10.1175/JHM-D-15-0157.1, 2016.

Kumar, S. V., Jasinski, M., Mocko, D., Rodell, M., Borak, J., Li, B., Kato Beaudoing, H., and Peters-Lidard, C. D.: NCALDAS land analysis: Development and performance of a multisensor, multi-variate land data assimilation system for the National Climate Assessment, J. Hydrometeorol., 20, 1571-1593, https://doi.org/10.1175/JHM-D-17-0125.1, 2018.

Kumar, S. V., Mocko, D. M., Wang, S., Peters-Lidard, C. D., and Borak, J.: Assimilation of remotely sensed Leaf Area Index into the Noah-MP land surface model: Impacts on water and carbon fluxes and states over the Continental U.S., J. Hydrometeorol., https://doi.org/10.1175/JHM-D-18-0237.1, 2019.

Lahoz, W. and De Lannoy, G.: Closing the gaps in our knowledge of the hydrological cycle over land: Conceptual problems, Surv. Geophys., 35, 577-606, 2014.

Leroux, D. J., Calvet, J.-C., Munier, S., and Albergel, C.: Using Satellite-Derived Vegetation Products to Evaluate LDAS-Monde over the Euro-Mediterranean Area, Remote Sens., 10, 1199, 2014.

Luo, L. and Wood, E. F.: Monitoring and predicting the 2007 U.S. drought, Geophys. Res. Lett., 34, L22702, https://doi.org/10.1029/2007GL031673, 2007.

Magnusson, L., Ferranti, L., and Vamborg, F.: Forecasting the 2018 European heatwave, ECMWF Newslett., 157, 4, available at: https://www.ecmwf.int/en/newsletter/157/editorial/more-data (last access: August 2020), 2018.

Mahfouf, J.-F., Bergaoui, K., Draper, C., Bouyssel, F., Taillefer, F., and Taseva, L.: A comparison of two offline soil analysis schemes for assimilation of screen level observations, J. Geophys. Res., 114, D08105, https://doi.org/10.1029/2008JD011077, 2009.

Martens, B., Miralles, D. G., Lievens, H., van der Schalie, R., de Jeu, R. A. M., Fernández-Prieto, D., Beck, H. E., Dorigo, W. A., and Verhoest, N. E. C.: GLEAM v3: satellite-based land evaporation and root-zone soil moisture, Geosci. Model Dev., 10, 19031925, https://doi.org/10.5194/gmd-10-1903-2017, 2017.

Massari, C., Camici, S., Ciabatta, L., and Brocca, L.: Exploiting Satellite-Based Surface Soil Moisture for Flood Forecasting in the Mediterranean Area: State Update Versus Rainfall Correction, Remote Sens., 10, 292, https://doi.org/10.3390/rs10020292, 2018.

Masson, V., Le Moigne, P., Martin, E., Faroux, S., Alias, A., Alkama, R., Belamari, S., Barbu, A., Boone, A., Bouyssel, F., Brousseau, P., Brun, E., Calvet, J.-C., Carrer, D., Decharme, B., Delire, C., Donier, S., Essaouini, K., Gibelin, A.-L., Giordani, H., Habets, F., Jidane, M., Kerdraon, G., Kourzeneva, E., Lafaysse, M., Lafont, S., Lebeaupin Brossier, C., Lemonsu, A., Mahfouf, J.-F., Marguinaud, P., Mokhtari, M., Morin, S., Pigeon, G., Salgado, R., Seity, Y., Taillefer, F., Tanguy, G., Tulet, P., Vincendon, B., Vionnet, V., and Voldoire, A.: The SURFEXv7.2 land and ocean surface platform for coupled or offline simulation of earth surface variables and fluxes, Geosci. Model Dev., 6, 929-960, https://doi.org/10.5194/gmd-6-929-2013, 2013.

McNally, A., Arsenault, K., Kumar, S., Shukla, S., Peterson, P., Wang, S., Funk, C., Peters-Lidard, C. P., and Verdin, J. P.: A land data assimilation system for sub-Saharan Africa food and water security applications, Sci. Data, 4, 170012, https://doi.org/10.1038/sdata.2017.12, 2017 
Miralles, D. G., De Jeu, R. A. M., Gash, J. H., Holmes, T. R. H., and Dolman, A. J.: Magnitude and variability of land evaporation and its components at the global scale, Hydrol. Earth Syst. Sci., 15, 967-981, https://doi.org/10.5194/hess-15-967-2011, 2011.

Mishra, A. K. and Singh, V. P.: A review of drought concepts, J. Hydrol., 391, 202-216, 2010.

Nash, J. E. and Sutcliffe, V.: River forecasting through conceptual models, J. Hydrol., 10, 282-290, 1970.

Noilhan, J. and Planton, S.: A simple parameterization of land surface processes for meteorological models, Mon. Weather Rev., 117, 536-549, https://doi.org/10.1175/15200493(1989)117<0536:ASPOLS>2.0.CO;2, 1989.

Noilhan, J. and Mahfouf, J.-F.: The ISBA land surface parameterisation scheme, Glob. Planet. Chang., 13, 145-159, 1996

Muñoz-Sabater, J., Lawrence, H., Albergel, C., Rosnay, P., Isaksen, L., Mecklenburg, S., Kerr, Y., and Drusch, M.: Assimilation of SMOS brightness temperatures in the ECMWF Integrated Forecasting System, Q. J. Roy. Meteorol. Soc., 2019, 2524-2548, https://doi.org/10.1002/qj.3577, 2019.

Munro, R., Eisinger, M., Anderson, C., Callies, J., Corpaccioli, E., Lang, R., Lefebvre, A., Livschitz, Y., and Perez Albinana, A.: GOME-2 on MetOp: From In-Orbit Verification to Routine Operations, in: Proceedings of the EUMETSAT Meteorological Satellite Conference, Helsinki, Finland, 12-16 June 2006.

Obasi, G. O. P.: WMO's role in the international decade for natural disaster reduction, B. Am. Meteorol. Soc., 75, 1655-1661, 1994.

Orsolini, Y., Wegmann, M., Dutra, E., Liu, B., Balsamo, G., Yang, K., de Rosnay, P., Zhu, C., Wang, W., Senan, R., and Arduini, G.: Evaluation of snow depth and snow cover over the Tibetan Plateau in global reanalyses using in situ and satellite remote sensing observations, The Cryosphere, 13, 2221-2239, https://doi.org/10.5194/tc-13-2221-2019, 2019.

Reichle, R. H., Koster, R. D., Liu, P., Mahanama, S. P. P., Njoku, E. G., and Owe, M.: Comparison and assimilation of global soil moisture retrievals from the Advanced Microwave Scanning Radiometer for the Earth Observing System (AMSR-E) and the Scanning Multichannel Microwave Radiometer (SMMR), J. Geophys. Res., 112, D09108, https://doi.org/10.1029/2006JD008033, 2007.

Reichle, R. H., Draper, C. S., Liu, Q., Girotto, M., Mahanama, S. P. P., Koster, R. D., and De Lannoy, G. J. M.: Assessment of MERRA-2 land surface hydrology estimates, J. Climate, 30, 2937-2960, https://doi.org/10.1175/JCLI-D-16-0720.1, 2017.

Reichle, R. H., Liu, Q., Koster, R. D., Crow, W. T., De Lannoy, G. J. M., Kimball, J. S., Ardizzone, J. V., Bosch, D., Colliander, A., Cosh, M., Kolassa, J., Mahanama, S. P., Prueger, J., Starks, P., and Walker, J. P.: Version 4 of the SMAP Level-4 Soil Moisture Algorithm and Data Product, J. Adv. Model. Earth Sy., 11, 31063130, https://doi.org/10.1029/2019MS001729, 2019.

Rodell, M., Houser, P. R., Jambor, U., Gottschalck, J., Mitchell, K., Meng, C.-J., Arsenault, K., Cosgrove, B., Radakovich, J., Bosilovich, M., Entin, J. K., Walker, J. P., Lohmann, D., and Toll, D.: The Global Land Data Assimilation System, B. Am. Meteor. Soc., 85, 381-394, 2004.

Rodríguez-Fernández, N., de Rosnay, P., Albergel, C., Richaume, P., Aires, F., Prigent, C., and Kerr, Y.: SMOS Neural Network Soil Moisture Data Assimilation in a Land Surface Model and Atmospheric Impact, Remote Sens., 11, 1334, https://doi.org/10.3390/rs11111334, 2019.
Rüdiger, C., Albergel, C., Mahfouf, J.-F., Calvet, J.-C., and Walker, J. P.: Evaluation of Jacobians for leaf area index data assimilation with an extended Kalman filter, J. Geophys. Res., 115, D09111, https://doi.org/10.1029/2009JD012912, 2010.

Sawada, Y. and Koike, T.: Simultaneous estimation of both hydrological and ecological parameters in an ecohydrological model by assimilating microwave signal, J. Geophys. Res.-Atmos, 119, 8839-8857, https://doi.org/10.1002/2014JD021536, 2014.

Sawada, Y., Koike, T., and Walker, J. P.: A land data assimilation system for simultaneous simulation of soil moisture and vegetation dynamics, J. Geophys. Res.-Atmos., 120, 5910-5930, https://doi.org/10.1002/2014JD022895, 2015.

Schellekens, J., Dutra, E., Martínez-de la Torre, A., Balsamo, G., van Dijk, A., Sperna Weiland, F., Minvielle, M., Calvet, J.-C., Decharme, B., Eisner, S., Fink, G., Flörke, M., Peßenteiner, S., van Beek, R., Polcher, J., Beck, H., Orth, R., Calton, B., Burke, S., Dorigo, W., and Weedon, G. P.: A global water resources ensemble of hydrological models: the eartH2Observe Tier-1 dataset, Earth Syst. Sci. Data, 9, 389-413, https://doi.org/10.5194/essd-9-389-2017, 2017.

Scipal, K., Drusch, M., and Wagner, W.: Assimilation of a ERS scatterometer derived soil moisture index in the ECMWF numerical weather prediction system, Adv. Water Resour., 31, 1101-1112, 2008.

Schlosser, A. and Dirmeyer, P.: Potential preditability of Eurasian snow cover, Atmos. Sci. Lett., 2, 1-8, 2001.

Shamambo, D. C., Bonan, B., Calvet, J.-C., Albergel, C., and Hahn, S.: Interpretation of ASCAT Radar Scatterometer Observations Over Land: A Case Study Over Southwestern France, Remote Sens., 11, 2842, https://doi.org/10.3390/rs11232842, 2019.

Svoboda, M., LeComte, D., Hayes, M., Heim, R., Gleason, K., Angel, J., Rippey, B, Tinker, R., Palecki, M., Stooksbury, D., Miskus, D., and Stephens, S.: The drought monitor, B. Am. Meteorol. Soc., 83, 1181-1190, 2002.

Tall, M., Albergel, C., Bonan, B., Zheng, Y., Guichard, F., Dramé, M. S., Gaye, A. T., Sintondji, L. O., Hountondji, F. C. C., Nikiema, P. M., and Calvet, J.-C.: Towards a Long-Term Reanalysis of Land Surface Variables over Western Africa: LDASMonde Applied over Burkina Faso from 2001 to 2018, Remote Sens., 11, 735, https://doi.org/10.3390/rs11060735, 2019.

Tramontana, G., Jung, M., Schwalm, C. R., Ichii, K., Camps-Valls, G., Ráduly, B., Reichstein, M., Arain, M. A., Cescatti, A., Kiely, G., Merbold, L., Serrano-Ortiz, P., Sickert, S., Wolf, S., and Papale, D.: Predicting carbon dioxide and energy fluxes across global FLUXNET sites with regression algorithms, Biogeosciences, 13, 4291-4313, https://doi.org/10.5194/bg-13-42912016, 2016.

Urraca, R., Huld, T., Gracia-Amillo, A., Martinez-de-Pison, F. J., Kaspar, F., and Sanz-Garcia, A.: Evaluation of global horizontal irradiance estimates from ERA5 and COSMO-REA6 reanalyses using ground and satellite-based data, Sol. Energy, 164, 339-354, 2018.

Van Loon, A. F.: Hydrological drought explained, WIREs Water, 2, 359-392, https://doi.org/10.1002/wat2.1085, 2015.

Voldoire, A., Decharme, B., Pianezze, J., Lebeaupin Brossier, C., Sevault, F., Seyfried, L., Garnier, V., Bielli, S., Valcke, S., Alias, A., Accensi, M., Ardhuin, F., Bouin, M.-N., Ducrocq, V., Faroux, S., Giordani, H., Léger, F., Marsaleix, P., Rainaud, R., Redelsperger, J.-L., Richard, E., and Riette, S.: 
SURFEX v8.0 interface with OASIS3-MCT to couple atmosphere with hydrology, ocean, waves and sea-ice models, from coastal to global scales, Geosci. Model Dev., 10, 4207-4227, https://doi.org/10.5194/gmd-10-4207-2017, 2017.

Wagner, W., Lemoine, G., and Rott, H.: A method for estimating soil moisture from ERS scatterometer and soil data, Remote Sens. Environ., 70, 191-207, 1999.

Wilhite, D. A.: Drought, a global assessment. Natural Hazards and Disasters Series, vol. 1, Routledge, London, UK, 2000.

World Meteorological Organization (WMO) and Global Water Partnership (GWP): Benefits of action and costs of inaction: Drought mitigation and preparedness - a literature review (N. Gerber and A. Mirzabaev, Integrated Drought Management Programme (IDMP) Working Paper 1, WMO, Geneva, Switzerland and GWP, Stockholm, Sweden, 2017.
Xia, Y., Mitchell, K., Ek, M., Sheffield, J., Cosgrove, B., Wood, E., Luo, L., Alonge, C., Wei, H., Meng, J., Livneh, B., Lettenmaier, D., Koren, V., Duan, Q., Mo, K., Fan, Y., and Mocko, D.: Continental-scale water and energy flux analysis and validation for the North American Land Data Assimilation System project phase 2 (NLDAS-2): 1. Intercomparison and application of model products, J. Geophys. Res., 117, D03109, https://doi.org/10.1029/2011JD016048, 2012a.

Xia, Y., Mitchell, K., Ek, M., Cosgrove, B., Sheffield, J., Luo, L., Alonge, C., Wei, H., Meng, J., Livneh, B., Duan, Q., and Lohmann, D.: Continental-scale water and energy flux analysis and validation for North American Land Data Assimilation System project phase 2 (NLDAS-2): 2. Validation of model-simulated streamflow, J. Geophys. Res., 117, D03110, https://doi.org/10.1029/2011JD016051, 2012b. 